DIW BERLIN

Discussion

Papers

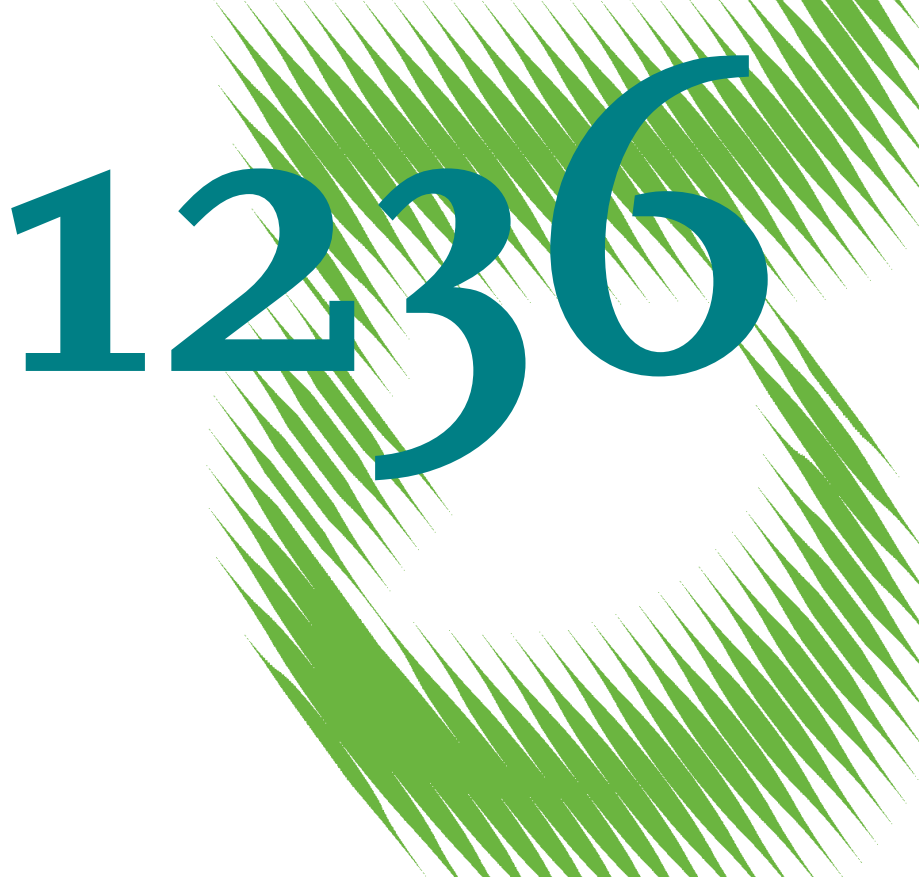

Appropriate Technology, Human Capital and

Development Accounting 
Opinions expressed in this paper are those of the author(s) and do not necessarily reflect views of the institute.

IMPRESSUM

(C) DIW Berlin, 2012

DIW Berlin

German Institute for Economic Research

Mohrenstr. 58

10117 Berlin

Tel. $+49(30) 89789-0$

Fax +49 (30) $89789-200$

http://www.diw.de

ISSN print edition $1433-0210$

ISSN electronic edition 1619-4535

Papers can be downloaded free of charge from the DIW Berlin website:

http://www.diw.de/discussionpapers

Discussion Papers of DIW Berlin are indexed in RePEc and SSRN:

http://ideas.repec.org/s/diw/diwwpp.html

http://www.ssrn.com/link/DIW-Berlin-German-Inst-Econ-Res.html 


\title{
Appropriate Technology, Human Capital and Development Accounting*
}

\author{
Areendam Chanda \\ Louisiana State University \\ Beatrice Farkas \\ DIW Berlin
}

June, 2012

\begin{abstract}
Over the past decade, research explaining cross country income differences has increasingly pointed to the dominant role of total factor productivity (TFP) gaps as opposed to factor accumulation. Nevertheless, it is a widely held belief that a country's ability to absorb and implement technologies is tied to its human capital. In this paper, we implement this idea in a novel specification and explore its quantitative implications within a development accounting framework. In our model, intermediate goods production takes place over a range of industries, and human capital ratios in a country influence industry specific productivities asymmetrically. As a result, in human capital abundant countries, production is concentrated around industries with high TFP, while in low human capital countries, production is concentrated around industries with low TFP. Development accounting exercises for a range of parameter values suggest that this human capital-technology complementarity may account for eighteen to twenty five percent of differences in GDP per worker which is higher than the combined direct contribution of factors of production.
\end{abstract}

Keywords: Development Accounting, Total Factor Productivity, TechnologySkill Complementarity, Appropriate Technology, Human Capital.

JEL Classification: O14, O3, O47

*Contacts: achanda@lsu.edu and bfarkas@diw.de. We are grateful to Eric Hillebrand, Shankha Chakraborty, Mihaela Craioveanu, Hildegnunn Stokke, Bulent Unel and seminar participants at CSAE Annual Conference on Development in Africa, Midwest Macroeconomic Meetings at Indiana University Bloomington, DEGIT Conference at UCLA, DIW-Berlin, and Louisiana State University for useful advice and comments. All errors are our own. 


\section{Introduction}

GDP per worker for the US stood at about thirty times than that of Ghana in 2005. What are the roots behind these enormous income differences across countries? Since the advent of new growth theory in the mid eighties, such questions have led to an explosion in research on economic growth. More specifically, over the past fifteen years, research has been spurred on by the finding that total factor productivity differences (TFP) account for a lion's share of proximate differences in GDP per worker. Most of this work uses development accounting as a framework where proximate determinants in output per worker can be decomposed into TFP, human capital and physical capital differences. Hsieh (2010) notes that TFP differences can account for fifty to seventy percent of the differences in GDP per worker. To understand the source of these TFP differences (and the lower roles for the two factors of production), research has followed a number of different paths. At the cost of making sweeping generalizations, these can be categorized into (i) understanding the underlying sources of these TFP differences which usually involve misallocation of resources across sectors and firms accompanied by heterogeneous productivity, (ii) revisiting the "partitioning" of the proximate causes into three non-overlapping categories, and (iii) measurement issues. ${ }^{1}$

In this paper we seek to re-examine the relative role of aggregate TFP differences in the context of appropriate technology and human capital endowments. In particular, we revisit the question - are all countries equally good at using all technologies? The trivial answer to this is no. Even though technology can flow freely across borders, the ability to adopt technologies will vary due to many reasons. As Acemoglu and Zilibotti (2001) note, this could be due to differences in human capital endowments or deeper determinants such as geography, culture, and history. Atkinson and Stiglitz (1969) and Basu and Weil (1998) note this could be due to differences in physical capital - labor ratios. In this paper, we focus on the role of differences in human capital.

The starting point of our analysis is that, at any point in time, there are some production technologies that have inherently high TFP. In a closed economy framework, if all countries wished to maximize their TFP, then they would naturally choose to produce in

\footnotetext{
${ }^{1}$ Rogerson and Restuccia (2008) is an example of work that suggests aggregate TFP differences can be attributed to misallocation of resources across plants that are heterogeneous in productivity. Research that reevaluates the role of partitioning includes Erosa, Koreshkova and Restuccia (2010) who revisit the effect of human capital on TFP, and Armenter and Lahiri (2011) who highlight the role of investment prices. Finally, examples of research that focus on measurement issues include Schoellman (2012) and Jones (2011), both of which reexamine the construction of human capital stocks. Needless to mention, this list is far from exhaustive. See Hsieh (2010) for a review of the literature.
} 
such industries. However, it is also true that these industries generally require high levels of human capital. For example, it should not take much motivation to convince the reader, that if Ghana had the resources, it would much rather be producing semiconductors instead of agricultural products or low skill manufacturing. However, given its skill endowments, Ghana specializes in the latter two. This line of reasoning also implicitly suggests that the high TFP in semiconductors come with a qualification - that the human capital content of labor be high as well. In other words, TFP is not exogenous. At the same time, using high levels of human capital in low skill agriculture or manufacturing confers no significant benefits in terms of TFP. Therefore in a decentralized economy endowed with high levels of human capital, there will be no gains from specializing in such sectors (except, due to consumer preferences). While these observations are in themselves not new, in this paper, we create a novel structure to capture these ideas, and relate them to comparisons of aggregate TFP levels undertaken in the literature.

We begin by decomposing total factor productivity into three distinct components. First, there is a sector neutral national homogeneous TFP component, a common assumption in the literature. This can reflect the overall ease with which technologies can enter an economy, or other aspects of efficiency that are not necessarily specific to firms, sectors or factor endowments. Second, we allow for variation in TFP levels across industries within a country which is independent of human capital. This component can be viewed as the innate productivity of the industry. Third, we introduce the concept of a human capital driven productivity component which is tied to the country's human capital abundance and affects industries asymmetrically. Thus, this too allows productivity to vary across industries but is endogenous to the country's human capital abundance. This third component gives some industries within a country a productivity advantage over other industries and may more than offset the innate productivity advantage.

To get an idea of how the last two features work, consider Figure 1. Here, industries are indexed along 0 to 1 arranged by their innate TFP. Industry 0 exhibits the lowest level of innate productivity and industry 1 has the highest. In Figure 1 Panel A, this inter-industry variation in technology which is independent of human capital is depicted by line III. Now consider two countries with different human capital endowments. For the country with a low level human capital (line I), the human capital specific aspect of productivity is maximized at an industry with a low innate TFP and for the country with high human capital (line II), this is maximized at an industry with a high innate TFP. In other words, human capital confers a productivity advantage to certain industries with higher human capital countries 
being able to benefit more from the high TFP industries. Thus lines I and II capture the notion of appropriate technology. Even though line III suggests that all countries could maximize TFP by specializing in industry 1, the human capital endowments suggest that countries might be more productive elsewhere along the continuum. Finally, industry TFP is a product of the human capital component as well as the innate component. ${ }^{2}$ The product is depicted in Figure 1 Panel B for the two countries respectively.

A few important inferences can be made right away. First, the manner in which lines I and II are drawn suggest that the further one goes away from the industry that maximizes TFP, the lower is the human capital based productivity. In other words, while there is an industry that is appropriate for the country's human capital endowment, the country could still very well produce in other industries and in some cases it might even be better off given the innate productivity level of industries further away. Indeed this is apparent in the case of country II where while the human capital component is maximized at less than 1 but industry 1 has the highest overall TFP. Secondly, note that lines I and II are drawn in a way that suggest that low human capital countries are disadvantaged in producing high TFP goods. However, high human capital countries are not as disadvantaged in producing less sophisticated goods. This asymmetry should appeal to one's intuition. A relatively uneducated worker in a poor country will not have the capabilities to operate hi-tech equipment which requires substantial investments of time and resources in human capital. On the other hand it is conceivable that a highly educated worker, with some training, can start working in an industry that does not require much human capital. Finally, note that for some industries (the ones with low innate TFP), the low human capital country is actually more productive than the rich country. However, we still need to multiply these with the country specific TFP components and if the differences in these are large enough across countries then the remaining two will be less relevant. In other words, appropriate technology will be less relevant. Thus, the structure is flexible in capturing a number of different scenarios.

In the next section of the paper, we present the actual mathematical formulation that allows us to capture this notion of appropriate technology. In section 3, we simulate the equilibrium solution of the model by using a standard development accounting approach in order to back out our measure for aggregate TFP (which is a product of all three components). We undertake a variance decomposition exercise for TFP (i.e., a TFP accounting exercise) and we find that differences in inter-industry TFP explains 18 to $25 \%$ of variation

\footnotetext{
${ }^{2}$ We ignore the industry neutral country specific component for the time being since that does not play a role in explaining inter-industry TFP's.
} 
in GDP per worker. After presenting the main results, we also undertake some sensitivity analysis with respect to the parameter values. Finally, we briefly dwell on the implication of our technology specification on diversification of industries. Section 4 concludes.

\subsection{Related Literature}

The idea of a country being better at using technologies specific to its capital-labor ratios dates back to Atkinson and Stiglitz (1969). Basu and Weil (1996) further build upon this concept of appropriate technology in a learning-by-doing model where improvements in technology are localized and tied to capital-labor ratios. While we draw inspiration from their work, we focus on human capital rather than physical capital. Needless to mention this is motivated by the large literature on skill-biased technological change as well as technologyskill complementarity. Closest to our paper, however are Caselli and Coleman (2006) and Acemoglu and Zilibotti (2001). Both of these papers already dwell on the notion of appropriate technology and human capital and therefore it is important to distinguish our contribution relative to theirs. At the outset, a key distinction is that our structure can be easily related to the development accounting literature and hence can make quantitative statements regarding aggregate TFP differences.

In Acemoglu and Zilibotti's model, the north which is relatively abundant in skills creates two types of technologies - those that complement skilled labor and those complement unskilled labor. The south which is relatively skill scarce imports these technologies costlessly. The decentralized solution is one where intermediate inputs over a range from zero to one can be partitioned into those that rely on skilled labor and complementary technologies and those that rely on unskilled labor and complementary technologies. The fact that the south is skill scarce, means that there is a range of intermediate inputs where it uses the skill-complementary technologies but with unskilled labor. This creates a productivity disadvantage for the south. The authors show that this mismatch has sizable effects on GDP per worker gaps. While our model is nowhere near as rigorous in terms of theory, there are some key differences. An important aspect of their paper is that TFP is similar across all industries in the north, whereas in the south it takes two values - high or low (relative to the north). In our model, we allow for a distribution of industry level TFP's to emerge in each countries that is not monotonic with indexation of industries along the $(0,1)$ continuum. Thus, as visualized earlier, the industry with the highest overall TFP does not have to be the one with the highest innate TFP.

Caselli and Coleman also develop a framework that also has two technologies, one that 
complements skilled workers $\left(A_{S}\right)$ while another complements unskilled workers $\left(\mathrm{A}_{U}\right)$. They introduce the concept of a technology possibility frontier and show that countries would optimally choose to locate along this frontier. Countries that are skill scarce will locate at a point where $A_{S}$ is low and $A_{U}$ is high, and vice-versa for the skill abundant countries. Moreover, the "height" of the production frontier reflects the skill neutral TFP differences. The fact that countries optimally choose to locate on a technology space and that productivity differences can be decomposed into an appropriate vs neutral component implies strong similarities with our model. Nevertheless the key difference remains that our structure is much more amenable to development accounting and secondly, we allow a distribution of TFP's to emerge within a country rather than restricting it to a set of two elements. Finally, the human capital externality in our structure implies that technology is not being chosen from an exogenously specified frontier, and is partly endogenous. Despite the differences, clearly our work complements both these papers. All three focus on the notion of appropriate technology and human capital but seek out to accomplish different goals, with ours being to relate it to development accounting and to make inferences about the distribution of TFP across industries.

\section{Model}

We consider a discrete-time model with a representative infinitely lived consumer who maximizes utility over a final homogeneous good. In addition to the final good, there is a continuum of intermediate inputs (which we will also loosely refer to as industries) which, in conjunction with capital, produce the final good. The intermediate inputs are produced using skilled labor and unskilled labor. In this section we solve for equilibrium GDP which depends on the equilibrium allocation of endowments across industries, which in turn is driven by our assumption of industry specific TFP. Using this equilibrium allocation, we derive expressions for aggregate TFP, and its inter-industry component.

\subsection{Production}

\subsubsection{Final good sector}

Perfectly competitive firms produce a homogeneous final good by combining capital and a continuum of differentiated intermediate inputs using a Cobb-Douglas production function,

$$
Y_{t}=K_{Y_{t}}^{1-\alpha} \int_{0}^{1} X_{i t}^{\alpha} d i, \quad 0<\alpha<1,
$$


where $K_{Y t}$ is the capital used in the production of final goods at time $t, X_{i t}$ is the amount of intermediate good $i$ used in final good production at time $t$ and $\alpha$ is the share of intermediate good $i$ in total output. ${ }^{3}$ From here on, we eliminate the time subscripts unless otherwise noted.

Final good producers maximize their profits,

$$
\pi=P_{Y} Y-(r+d) K_{Y}-\int_{0}^{1} p_{i} X_{i} d i
$$

where $r$ is the interest rate and $d$ is the depreciation rate. To simplify matters, we assume that from now on the depreciation rate is 1 . Further, we set the final good as the numeraire good, with $P_{Y}=1$. First order conditions imply that the conditional demand functions for intermediate input, $X_{i}$, and capital, $K_{Y}$ are,

$$
\begin{gathered}
X_{i}=\left[\frac{p_{i}}{\alpha}\right]^{\frac{1}{\alpha-1}} K_{Y} \\
1+r=(1-\alpha) \frac{Y}{K_{Y}}
\end{gathered}
$$

\subsubsection{Intermediate goods sector}

The intermediate goods sector consists of a continuum of differentiated varieties $i$ that are indexed from 0 to 1 and is characterized by monopolistic competition. Each variety, $i$, is produced by a single firm according to the following production function,

$$
X_{i}=A(i, h) L_{i}^{\delta} H_{i}^{1-\delta}
$$

where $L_{i}$ and $H_{i}$ represent the amount of unskilled and skilled labor used in the production of variety $i$ and $\delta$ is the share of unskilled labor. $A(i, h)$ represents the TFP level of the firm and we will elaborate on this below.

We assume that each country faces the following resource constraints,

$$
\int_{0}^{1} H_{i} d i=H \quad \int_{0}^{1} L_{i} d i=L
$$

where $L$ and $H$ represent the fixed supply of total unskilled and skilled labor in the economy.

\footnotetext{
${ }^{3}$ It might seem odd that our final goods production does not explicitly include any labor input. This is purely a simplifying assumption since, as we shall see shortly, the intermediate goods are produced entirely from labor. Ultimately, with an eye towards the development accounting exercise, we do need to include both physical capital and labor and this structure allows us to incorporate physical capital in a way that does not complicate things unnecessarily.
} 
Technology As alluded to earlier in the introduction, the characterization of technology is the centerpiece of the model. Technology (or TFP) is assumed to comprise of three separate parts - a part that is country specific but neutral to industry and human capital, a part that is industry specific but neither country nor human capital specific, and finally a part that is dependent upon local human capital endowments and the industry location along the index of 0 to 1 . All of these are captured using the following functional form,

$$
A(i, h)=B e^{\mu i} e^{-\frac{1}{2}\left(\ln \frac{h}{i}\right)^{2}},
$$

where $B$ is the country-specific productivity index which we assume grows at an exogenous rate $\phi . e^{\mu i}$ is the industry specific component of technology that reflects innate TFP. $e^{-\frac{1}{2}\left(\ln \frac{h}{i}\right)^{2}}$ is the human capital specific component of technology, where $h$ represents a measure of human capital abundance that ranges from zero to one. The innate TFP component is simply an exponential function that allows for a smooth growth in productivity from one industry to the next along the continuum. Higher values for $\mu$ implies greater innate differences across varieties. All else being equal, countries would prefer at any point in time to specialize in industry 1 . We do not make any assumptions about intertemporal growth in innate TFP. The fact that $B$ is assumed to grow at a constant rate can also be re-interpreted as all industries in the country experiencing similar rates of innate TFP growth.

To capture the productivity benefits from producing in an industry that gains most from the country's human capital abundance, we assume a functional form that is inspired by the log-normal distribution. The value that the function takes depends on both $h$ and $i$. It is easy to see that the value of this function is maximized when $h=i$. Hence, our definition of $h$ needs to conform to a scale of 0 to 1 . In our quantitative exercise in the next section we define this as ratio of skilled labor input to all labor input in an economy. When firms choose to produce in an industry $i$ that is further away from $h$, clearly the human capital component of TFP diminishes. It should also be clear, that the human capital externality always has a maximum value of 1 . In other words, the externality, per se, does not advantage one country over the other when making aggregate TFP comparisons. It advantages countries to the extent that the maximizing industry has a higher or lower innate TFP $\left(e^{\mu i}\right)$.

Figures 2 reproduces the earlier figure with values now shown explicitly with $h=0.2$ and $h=0.8$. One might wonder why we do not choose a simpler function such as $e^{-\frac{1}{2}(h-i)^{2}}$. One of the key differences between the log specification and this one is the asymmetric nature of benefits of human capital. In the latter case, as industries locate further away from $i=h$, the human capital based TFP exhibits a smooth decline (i.e. symmetric, as in a normal distribution). However, in our log based specification, the decline is asymmetric. We believe 
this is closer to reality. Countries with low levels of $h$ will see their productivity diminish rapidly if they produce in industries with high values of $i$. On the other hand, for countries with high values of $h$, productivity in lower $i$ industries will not decline rapidly. To put it in simpler terms, skilled workers can do many of the tasks that unskilled workers can but not vice versa. ${ }^{4}$ Finally, the fraction, $1 / 2$, is present mainly to make the algebra less cumbersome.

Having discussed the human capital component, we can now broach the notion of innate TFP again. Innate TFP can also be labeled as "potential TFP". To see this note that concentrating production at $i=1$ is an option that is available to everyone. However, this makes sense only if $e^{(\mu \times 1)} e^{-\frac{1}{2}\left(\ln \frac{h}{1}\right)^{2}}=e^{(\mu \times 1)}$. However, for any country that has $h<1$., it is the case that $e^{(\mu \times 1)} e^{-\frac{1}{2}\left(\ln \frac{h}{1}\right)^{2}}<e^{(\mu \times 1)}$. In other words the full potential of producing at $i=1$ are not realized. When countries specialize at $i=h$, they reach the potential TFP of that specific sector.

Entry and Profit Maximization As with product variety models, while there are monopoly profits for the producer of each variety, there is also free entry. To gain monopoly rights for a producing a specific variety, firms bid for production rights. Thus there is a competitive entry fee. For an equilibrium to exist, the entry fee must be equal to the present discounted value of monopoly profits. ${ }^{5}$ Therefore, if we define $V_{i t}=\pi_{i, t+1} /(1+r)$, in equilibrium, the free-entry condition is,

$$
\frac{\pi_{t+1}}{1+r}=F_{i t}
$$

In period $t+1$, the firm makes all pricing and output decisions that maximize its monopoly profits. Given (4), the cost function for the producer of variety $i$ is:

$$
C\left(w_{L_{i}}, w_{H_{i}}, X_{i}\right)=\frac{1}{A(i, h)} \frac{\delta^{-\delta}}{(1-\delta)^{1-\delta}} w_{L_{i}}^{\delta} w_{H_{i}}^{1-\delta} X_{i}
$$

where $w_{L_{i}}$ and $w_{H_{i}}$ are the wages for skilled and unskilled labor respectively. Each monopolist maximizes its profits each period,

$$
\max \pi(i)=p_{i} X_{i}-C\left(w_{L_{i}}, w_{H_{i}}, X_{i}\right)
$$

\footnotetext{
${ }^{4}$ Another advantage of having a log specification is that it allows us to work with growth rates of human capital. While that is not something we pursue in this version of the paper, we did calculate it in earlier versions. There is, however, also a drawback with the log specification - namely, the industry at $i=0$ never has productivity defined and the entire structure only works for $h$ strictly greater than zero. In other words, the range of industries should strictly be viewed as $i \in(0,1]$.

${ }^{5}$ Since, we are writing a two period model, the entry fee must be paid every time period to ensure monopoly rights in the next time period.
} 
The first order conditions give the optimal price charged by the monopolist, which represents a standard markup of $1 / \alpha$ over the marginal cost of manufacturing intermediate goods,

$$
p_{i}=\frac{1}{\alpha} \frac{1}{A(i, h)} \frac{\delta^{-\delta}}{(1-\delta)^{1-\delta}} w_{L_{i}}^{\delta} w_{H_{i}}^{1-\delta}
$$

as well as wages, $w_{L_{i}}$ and $w_{H_{i}}$,

$$
\begin{gathered}
w_{L_{i}}=\delta \alpha^{2} K_{Y}^{1-\alpha} Y A(i, h)^{\alpha} L_{i}{ }^{\alpha \delta-1} H_{i}{ }^{(1-\delta) \alpha} \\
w_{H_{i}}=(1-\delta) \alpha^{2} K_{Y}^{1-\alpha} A(i, h)^{\alpha} L_{i}^{\alpha \delta} H_{i}{ }^{(1-\delta) \alpha-1}
\end{gathered}
$$

Therefore, all pricing and output decisions of the firm are influenced by $A(i, h)$. Equations (2) and (8) yield the demand $X_{i}$ :

$$
X_{i}=\left[\frac{1}{\alpha^{2}} \frac{1}{A(i, h)} \frac{\delta^{-\delta}}{(1-\delta)^{1-\delta}} w_{L_{i}}^{\delta} w_{H_{i}}^{1-\delta}\right]^{\frac{1}{\alpha-1}} K_{Y}
$$

Next, using equations (8) and (11) we solve for profits $\pi_{i}$ in order to back out $F_{i}$ from the free-entry condition (7). Thus,

$$
F_{i}=\frac{\pi_{t+1}(i)}{1+r}=\frac{1}{1+r}(1-\alpha) \alpha^{\frac{1+\alpha}{1-\alpha}} A(i, h)^{\frac{\alpha}{1-\alpha}}\left[\frac{\delta^{-\delta}}{(1-\delta)^{1-\delta}} w_{L_{i}}^{\delta} w_{H_{i}}^{1-\delta}\right]^{\frac{\alpha}{\alpha-1}} K_{Y}
$$

Equation (12) implies that the entry costs $F_{i}$ are an increasing function of the firm's TFP, $A(i, h)$. Potential entrants will pay higher fees for industries with higher TFP. Integrating over all industries $i \in(0,1]$, we can calculate the total amount of entry costs,

$$
F=\int_{0}^{1} F_{i} d i=\frac{1}{1+r}(1-\alpha) \alpha^{\frac{1+\alpha}{1-\alpha}}\left[\frac{\delta^{-\delta}}{(1-\delta)^{1-\delta}} w_{L_{i}}^{\delta} w_{H_{i}}^{1-\delta}\right]^{\frac{\alpha}{\alpha-1}} \int_{0}^{1} A(i, h)^{\frac{\alpha}{1-\alpha}} d i K_{Y}
$$

\subsection{Consumers}

The economy is populated by infinitely lived identical consumers of mass 1, with zero population growth. Consumers maximize the present discounted value of their lifetime utility function:

$$
\max \sum_{t=0}^{\infty} \beta^{t} u\left(C_{t}\right), \quad u\left(C_{t}\right)=\frac{C_{t}^{1-\sigma}-1}{1-\sigma}
$$

where $\beta>0$ is the discount rate, $\sigma$ is the inverse of intertemporal elasticity of substitution and $u\left(C_{t}\right)$, the felicity function reflects constant relative risk aversion. The budget constraint of each consumer is given by:

$$
D_{t+1}=C_{t}+w_{H} H_{t}+w_{L} L_{t}+(1+r) D_{t},
$$


where $D_{t}$ represents total asset holdings at time t, $w_{H} H+w_{L} L$ is the wage income, and $r$ is the interest rate. $C_{t}$ is consumption of the final good. Optimization yields the standard Euler equation results,

$$
\beta \frac{U^{\prime}\left(C_{t+1}\right)}{U^{\prime}\left(C_{t}\right)}=\frac{1}{1+r}
$$

In other words $\left[C_{t+1} / C_{t}\right]^{-\sigma}=1 /[\beta(1+r)]$. Thus the growth rate of $C_{t}$ is

$$
g_{C}=\frac{C_{t+1}-C_{t}}{C_{t}}=[\beta(1+r)]^{\frac{1}{\sigma}}-1
$$

\subsection{General equilibrium}

The decentralized equilibrium solution of the model is defined as one where firms maximize their profits, consumers maximize their utility, and input and output markets clear. Market clearing is defined by the following conditions,

$$
\begin{gathered}
Y=C+I \\
K=K_{Y}+F \\
L=\int_{0}^{1} L_{i} d i ; \quad H=\int_{0}^{1} H_{i} d i
\end{gathered}
$$

In the second condition, physical capital actually used in production process as well as entry fees are lumped together as capital. We include the entry fee here to reflect the fact that like physical capital, ultimately it earns a rate of return that is equal to the interest rate and that also needs to be "invested" upfront with the return earned in the next period. Each period $K_{Y}$ fully depreciates, thus $K_{t+1}=I_{t}=Y_{t}-C_{t}$, where $I_{t}$ is total amount of investments and by construction is equal to $K_{Y, t}+F_{t}$. $C_{t}$ is consumption at time $t$. The third condition characterizes the market clearing conditions for both types of labor.

In equilibrium, nominal wages are equalized such that $w_{L_{i}}=w_{L}$ and $w_{H_{i}}=w_{H}$ for $i \in(0,1]$. Using $(9)$ and (10) the variety specific demands for unskilled labor $L_{i}$ and human capital $H_{i}$ are expressed as functions of nominal wages and technology,

$$
\begin{gathered}
L_{i}=\alpha^{\frac{2}{1-\alpha}} \delta^{\frac{1-\alpha(1-\delta)}{1-\alpha}}(1-\delta)^{\frac{\alpha(1-\delta)}{1-\alpha}} K_{Y} w_{L}^{\frac{\alpha(1-\delta)-1}{1-\alpha}} w_{H}^{\frac{-\alpha(1-\delta)}{1-\alpha}} A(i, h)^{\frac{\alpha}{1-\alpha}} \\
H_{i}=\alpha^{\frac{2}{1-\alpha}} \delta^{\frac{\alpha \delta}{1-\alpha}}(1-\delta)^{\frac{-\alpha \delta+1}{1-\alpha}} K_{Y} w_{L}^{\frac{-\alpha \delta}{1-\alpha}} w_{H}^{\frac{\alpha \delta-1}{1-\alpha}} A(i, h)^{\frac{\alpha}{1-\alpha}}
\end{gathered}
$$

In order to derive $w_{L}$ and $w_{H}$ as functions of skill endowments and technologies, we substitute the above equations into the labor market equilibrium conditions. Thus equilibrium nominal wages are given by: 


$$
\begin{gathered}
w_{L}=\alpha^{2} \delta K_{Y}^{1-\alpha} L^{\alpha \delta-1} H^{\alpha(1-\delta)}\left[\int_{0}^{1} A(i, h)^{\frac{\alpha}{1-\alpha}} d i\right]^{1-\alpha} \\
w_{H}=\alpha^{2}(1-\delta) K_{Y}^{1-\alpha} L^{\alpha \delta} H^{\alpha(1-\delta)-1}\left[\int_{0}^{1} A(i, h)^{\frac{\alpha}{1-\alpha}} d i\right]^{1-\alpha}
\end{gathered}
$$

Next, we substitute the equilibrium nominal wages from (17) and (18) into the demand of $X_{i}$ given by (11). We can now substitute the explicit demand for intermediates $X_{i}$ into the production function of the aggregate output from (1). Thus in equilibrium, aggregate income is:

$$
Y=K_{Y}^{1-\alpha} L^{\alpha \delta} H^{\alpha(1-\delta)} \int_{0}^{1} A(i, h)^{\frac{\alpha}{1-\alpha}}\left[\int_{0}^{1} A(i, h)^{\frac{\alpha}{1-\alpha}} d i\right]^{-\alpha} d i
$$

Equation (19) separates the factors of accumulation from the TFP components. In order to get a cleaner expression for TFP, denote $g(i)=A(i, h)^{\frac{\alpha}{1-\alpha}}$. Furthermore, denote the definite integral, $G=\int_{0}^{1} g(i)$. It is easy to see that,

$$
\int_{0}^{1} g(i)\left[\int_{0}^{1} g(i) d i\right]^{-\alpha} d i=\int_{0}^{1} g(i) G^{-\alpha} d i=G^{1-\alpha}
$$

Moreover, observe that

$$
G=\left[\int_{0}^{1} g(i) d i\right]^{1-\alpha}
$$

This allows us to express GDP as a function of endowments and industry-level TFP's,

$$
Y=K_{Y}^{1-\alpha} L^{\alpha \delta} H^{\alpha(1-\delta)}\left[\int_{0}^{1} A(i, h)^{\frac{\alpha}{1-\alpha}} d i\right]^{1-\alpha}
$$

In other words, GDP reduces to a standard Cobb Douglas production function of three factor inputs and a TFP term. The TFP term is an integral of industry specific TFP's. An interesting result here is that the definite integral is not weighted by industry employment shares. This is mainly a result of the Cobb-Douglas structure which allows all the input quantities to collapse into the aggregate measures of $L$ and $H$. Therefore, while as we shall see later in the paper, there is a distribution of industries and employment that is driven by productivity differences, the actual calculation of aggregate TFP is not affected by this distribution. Next, we substitute the formula for $A(i, h)$ given by (6) into (20). Notice that,

$$
\left[\int_{0}^{1} A(i, h)^{\frac{\alpha}{1-\alpha}} d i\right]^{1-\alpha}=B_{t}^{\alpha}\left[\int_{0}^{1}\left[e^{\mu i} e^{\frac{-1}{2}\left(\ln \frac{h}{i}\right)^{2}}\right]^{\frac{\alpha}{1-\alpha}} d i\right]^{1-\alpha}
$$

Define,

$$
Z \equiv \int_{0}^{1}\left[e^{\mu i} e^{\frac{-1}{2}\left(\ln \frac{h}{i}\right)^{2}}\right]^{\frac{\alpha}{1-\alpha}} d i
$$


Therefore, $Z$ can be viewed as representing an aggregated inter-industry TFP which reflects both the distribution of innate TFP's and the human capital component . Then, GDP from (20) can be further simplified to,

$$
Y=K_{Y}^{1-\alpha} L^{\alpha \delta} H^{\alpha(1-\delta)} B_{t}^{\alpha} Z^{1-\alpha}
$$

Next, we solve for aggregate fixed costs, $F$. In a similar fashion as solving for $Y$, we substitute the nominal wage from (9) and (10) into the expression of $F$ given by (13),

$$
F=\frac{1}{1+r} \alpha(1-\alpha) K_{Y}^{1-\alpha} L^{\alpha \delta} H^{\alpha(1-\delta)}\left[\int_{0}^{1} A(i, h)^{\frac{\alpha}{1-\alpha}} d i\right]^{1-\alpha} .
$$

After substituting the interest rate from (3) into the above equation, we get $F=\alpha K_{Y}$ which implies that $K_{Y}=\frac{1}{1+\alpha} K$. This allows us to rewrite the GDP equation completely in terms of exogenous resource endowments,

$$
Y=\left(\frac{1}{1+\alpha}\right)^{1-\alpha} K^{1-\alpha} L^{\alpha \delta} H^{\alpha(1-\delta)} B_{t}^{\alpha} Z^{1-\alpha}
$$

Finally, we close the model by solving for the endogenous interest rate $r$. Along BGP, all variables grow at constant rates (i.e., $g_{K}, g_{Y}$, and $g_{C}$ are constant). Therefore, the growth rate of capital-output ratio is zero on BGP, which implies that $g_{K}=g_{Y}$. Since total capital is given by $K=((1+\alpha) / \alpha) F$, we use (23) to solve for $g_{K}=\left(K_{t+1}-K_{t}\right) / K_{t}$,

$$
\begin{gathered}
g_{K}=\frac{K_{t+1}}{K_{t}}-1=\frac{K_{Y_{t+1}}\left[\int_{0}^{1} A_{t+1}(i, h)^{\frac{\alpha}{1-\alpha}} d i\right]^{1-\alpha}}{K_{Y_{t}}\left[\int_{0}^{1} A_{t}(i, h)^{\frac{\alpha}{1-\alpha}} d i\right]^{1-\alpha}}-1=\left(1+g_{K}\right)^{1-\alpha} \frac{B_{t+1}^{\alpha}\left[\int_{0}^{1}\left[e^{\mu i} e^{\frac{-1}{2}\left(\ln \frac{h}{i}\right)^{2}}\right]^{\frac{\alpha}{1-\alpha}} d i\right]^{1-\alpha}}{B_{t}^{\alpha}\left[\int_{0}^{1}\left[e^{\mu i} e^{\frac{-1}{2}\left(\ln \frac{h}{i}\right)^{2}}\right]^{\frac{\alpha}{1-\alpha}} d i\right]^{1-\alpha}-1} \\
g_{K}=\left(1+g_{K}\right)^{1-\alpha}(1+\phi)^{\alpha}-1
\end{gathered}
$$

Therefore,

$$
g_{K}=\phi
$$

The growth rate of physical capital is equal to the exogenous rate of growth of productivity. In equilibrium, $\left(1+g_{K}\right) \frac{K_{t}}{Y_{t}}=1-\frac{C_{t}}{Y_{t}}$ therefore $g_{K}=g_{C}$. Using (16) and (25) we back out a standard expression for the endogenous interest rate $r$,

$$
r=\frac{(1+\phi)^{\sigma}-\beta}{\beta}
$$




\section{Development Accounting}

To undertake a quantitative analysis of the role of appropriate technology and human capital, we proceed in two steps. First we repeat the development accounting exercise that involves the calculation of aggregate TFP as has been done in earlier research. This is similar to the exercises in Hall and Jones (1999) and Klenow and Rodriguez-Clare (1997) but with updated data and a slightly different production function for final output. Secondly, aggregate TFP itself can be decomposed into two different parts - the first part reflects the aggregate interindustry TFP and is driven by variations in innate TFP and the human-capital component. The second part reflects the industry and human capital neutral component of TFP $(B)$. The accounting exercise is based on equation (22). We begin by rewriting the equation in terms of GDP per worker and using physical capital-output ratios instead of physical capital per worker,

$$
y \equiv \frac{Y}{N}=\left[\frac{K_{Y}}{Y}\right]^{\frac{1-\alpha}{\alpha}}\left(\frac{L}{N}\right)^{\delta}\left(\frac{H}{N}\right)^{(1-\delta)} B Z^{\frac{1-\alpha}{\alpha}}
$$

where, $L / N$ is a measure of unskilled labor input relative to the total workers and $H / N$ is a measure skilled labor input relative to total workers. ${ }^{6}$ Note that aggregate TFP, as conventionally measured is now a product of $B$ and $Z^{\frac{1-\alpha}{\alpha}}$,

$$
T F P=B Z^{\frac{1-\alpha}{\alpha}}
$$

where $Z^{\frac{1-\alpha}{\alpha}}$ reflects inter-industry TFP. This also captures the role played by the human capital component. Hence, one can argue that $Z^{\frac{1-\alpha}{\alpha}}$ should really be attributed to human capital rather than TFP. This is true though at the same time the fact that $Z^{\frac{1-\alpha}{\alpha}}$ also captures innate TFP means that it is not limited to human capital. Therefore, in our results we will emphasize the relative contribution of inter-industry TFP to aggregate TFP, rather than get into a human capital vs TFP debate. Another important difference between equation (27) and the equations in Hall and Jones is that the labor input here is the geometric mean of two terms, unskilled labor input per worker and skilled labor input per worker,

$$
\left(\frac{L}{N}\right)^{\delta}\left(\frac{H}{N}\right)^{(1-\delta)}
$$

In Hall and Jones, it is simply human capital per worker. This is because in their paper there is no real differentiation between skilled workers vs unskilled workers. In this respect

\footnotetext{
${ }^{6}$ We should clarify that skilled labor, $H$, is a measure of human capital input beyond a threshold. Similarly, $L$, represents a measure of unskilled labor. It is important to note that $H+L \neq N$. N does not have any "augmentation" and is only the actual number of workers.
} 
our formulation is closer to Klenow and Rodriguez-Clare who make distinctions between skilled and unskilled workers. This also implies that how we distinguish between skilled vs unskilled will have an effect on aggregate TFP. Changes in the threshold will not only change the values of the two fractions in (29), but will also change the value of inter-industry TFP. ${ }^{7}$ Indeed, much of our discussion in the quantitative exercises is driven by the choice of the threshold.

\subsection{Data}

The Data for GDP per worker $(y)$, investment shares, and population are extracted from Penn World Tables 7.0 that use 2005 as the base year. ${ }^{8}$ Capital stocks $(K)$ are calculated by using the perpetual inventory approach as described in Hall and Jones (1999) using 1970 as the steady state values. To construct measures of skilled and unskilled labor, we need information on years of schooling, duration of various levels of schooling and returns to schooling. Barro and Lee (2011) provide data for educational attainment for population aged 15 and over. They break each country's labor force into seven categories of educational attainment: no schooling, some primary, completed primary, some secondary, completed secondary, some tertiary, and completed tertiary. Secondly, Caselli and Coleman (2006) report the durations of primary and secondary education as well as the private returns from schooling for each country considered. Based on these datasets, we construct different measures for human capital by using the Mincerian approach. We stick to Caselli and Coleman's strategy of constructing these numbers. The standard Mincerian wage regression states that there is a linear relationship between the log of wage and the returns from schooling. Specifically, $\log w_{j}=\beta_{0}+\beta_{1} \lambda_{j}+\epsilon_{j}$, where $\lambda_{j}$ represents average years of schooling for individual $j$. The coefficient $\beta_{1}$ captures the Mincerian private returns to schooling and reflects a $100 \times \beta_{1}$ percentage increase in wages due to an additional year of schooling.

The stocks of unskilled labor and skilled labor (human capital) for each country are calculated as,

$$
L=N \frac{S_{1} e^{\beta \lambda_{1}}+\ldots+S_{i} e^{\beta \lambda_{j}}}{e^{\beta \lambda_{1}}}
$$

and,

$$
H=N \frac{S_{j+1} e^{\beta \lambda_{j+1}}+\ldots+S_{7} e^{\beta \lambda_{7}}}{e^{\beta \lambda_{j+1}}},
$$

\footnotetext{
${ }^{7}$ This is also true in Klenow and Rodriguez-Clare where their measure of TFP changes with changes in the education threshold used to distinguish between $H$ and $L$.

${ }^{8}$ See Heston, Summers and Atten (2011).
} 
where $S_{1}, S_{2}, \ldots, S_{7}$ are the fractions of labor force $N$ that have no schooling, some primary education, $\ldots$, completed tertiary education. $\beta$ is the country-specific private return to education and $\lambda_{1}, \ldots, \lambda_{7}$ are the durations in years of each educational level for a given country. Since there is a disparity across countries in terms of duration of educational levels, we rescale $L$ and $H$ based on the fact that in our set of countries, the shortest length of primary education is four years and six years for secondary education. Therefore, we multiply $H$ by $e^{\beta\left(\lambda_{3}+\lambda_{5}-10\right)} .9$

The main question concerns the placement of the threshold $j$, i.e, what constitutes unskilled labor and what consists human capital/skilled labor? There is no unambiguous reason to choose a certain level of attainment over another. In the case of developed countries it is now well known that skill biased technological change (SBTC) has disproportionately benefited college educated workers relative to high school educated workers. Hence a specification which creates a partition between those who have completed secondary education versus higher groups makes sense. However, for developing economies it is not clear what the correct differentiator is. Theoretically, in our model, since both types of countries draw from the same set of technologies, the threshold too should be the same. Applying this logic would imply labeling skilled workers as those having some tertiary education or higher for both sets of countries. Nevertheless in other cross-country studies such as Caselli and Coleman (2006) and Chmelarova and Papageorgiou (2005), literacy is used as a threshold. Mankiw, Romer and Weil (1992), on the other hand, is well known for using a modified measure of secondary enrollment as a measure of investment in human capital. For our work, we use completed secondary education as a threshold for defining skilled labor.The choice for the first threshold is mainly motivated by the data. There is very little variation in human capital measures once one uses a lower barrier such as completed primary (and worse for even lower ones such as incomplete primary). This is not surprising - including primary education as a measure of skills destroys all variation in the measure of human capital per worker as a factor of production let alone the human capital component of TFP. ${ }^{10}$ It is one of the underlying reasons why Mankiw, Romer and Weil chose secondary enrollment as their measure for investment in education. ${ }^{11}$ Apart from data, it also makes sense that completed

\footnotetext{
${ }^{9}$ From Caselli and Coleman (2006) we have country specific durations of primary and secondary education. For subgroups that did not complete the respective levels of study (some primary, some secondary, some tertiary), like them, we use, half of the duration of that level.

${ }^{10}$ In our preliminary analysis, with primary completed as being the threshold, variations in aggregate TFP differences were $125 \%$ of that of output per worker, rendering variance decomposition exercises meaningless.

${ }^{11}$ One of the reasons why Klenow and Rodriguez Clare (1997) can show a greater role for TFP relative to human capital is because they modify MRW's variable by adding primary enrollment. Indeed that is the
} 
secondary schooling be chosen as a threshold. Even in developing economies, getting a high school diploma forms the basis for entry into the formal private, and government sector jobs. Finally, almost all the papers referred here ranging from Mankiw, Romer and Weil (1992) to Caselli and Coleman (2006) have used 1985 as their end point of the time period of study, or the single year for their calibration exercises. However, our calculations are based on 2005 data. In the intervening twenty years, developing countries have made significant enough strides in educational attainments that it makes more sense to use a higher threshold. ${ }^{12}$ In addition to completed secondary, we also report results using some tertiary as the threshold which is obviously motivated by the SBTC literature.

To calibrate the model we need empirical estimates for parameters $\alpha, \delta$, and $\mu$. For the share of capital in aggregate output, we set $1-\alpha=1 / 3$ (see Gollin (2002)). $\delta$ separates the share of skilled vs unskilled workers in the total wage bill. There are no clear empirical counterparts to this. The closest we have are estimates by Weil (2009) that suggest the share of human capital, our equivalent of $1-\delta$, in the total wage bill is 0.5 for developing economies and 0.65 for developed economies, i.e. $\delta=0.5$ and 0.35 respectively. However $\delta$ reflects no schooling and ignores everything beyond. Therefore, they would be an underestimate for our work. As a compromise between increasing the values and making a single choice for both developing and developed economies, we adopt $\delta=0.5$. We revisit the choice of $\delta$ when we undertake sensitivity analysis with respect to parameter values. Finally, we need values for the parameter, $\mu$, which reflects innate TFP. We initially set $\mu=1$ which implies that the innate TFP of industries at $i=0.9$ relative to $i=0.1$ is 2.2 . Later on, we undertake a sensitivity analysis and set $\mu=0.5$ and $\mu=1.5$ which imply a ratio of innate TFP of 1.5 and 3.3, respectively. Given the large productivity differences that exist across sectors in developing countries, even $\mu=1.5$ with an innate TFP ratio of 3.3 may seem like an underestimate. $^{13}$ Nevertheless, the larger the $\mu$, the greater the role of inter-industry TFP single most important reason in their analysis that causes the reallocation of roles. Human capital's role drops from $48 \%$ to $11 \%$ and TFP jumps from $20 \%$ to $60 \%$ because of this single change. See Table 1 in their paper.

${ }^{12}$ Comparing 2005 to 1985 for the countries in our sample, the mean primary completion rate had gone up from $60 \%$ to $80 \%$ during this 25 year period. All countries in our sample, except Guatemala, had registered $60 \%$ or more primary completion rates by 2005 .

${ }^{13}$ Chanda and Dalgaard (2008) note that agricultural labor productivity in the economy for some countries is less than $10 \%$ relative to labor productivity in the non-agricultural sector of the economy. While these are labor productivity numbers and not TFP, Caselli (2005) argues that almost all of the differences in sectoral labor productivity are due to differences in TFP. Vollrath (2009) however takes a different view arguing that it is inefficiency in factor markets rather than TFP differences that cause these gigantic labor productivity 
$\left(Z^{\frac{1-\alpha}{\alpha}}\right)$ and hence our values would only be downplaying its role in explaining productivity differences.

\subsection{Calibration}

We calibrate the equilibrium solution of the model given by (27) using a cross-section of 51 countries for the year 2005. Table 1 presents the summary statistics of the key variables - GDP per worker $(y)$, capital output ratio $(K / Y)$, unskilled labor input per worker $(L / N)$ skilled labor input per worker $(H / N)$ and the human capital abundance measure $(h=H /(H+L))$. For GDP per worker, capital output ratio and $h$ the values are actual magnitudes whereas the labor input measures are relative to the US.

The data reflect large income dispersion across countries: Ghana, the country with the lowest standard of living from our sample of countries, has $3.2 \%$ of U.S GDP per worker. There is also large variation in human capital abundance across countries. Using completed secondary education as a threshold, Guatemala's value is ten percent of the US. Ghana, however, which is the next lowest country has twenty percent of the US value. If we use some tertiary education as the threshold, both Ghana and Guatemala fall to about seven percent of the US value. In addition to summary statistics, we also present the correlations between GDP per worker and the remaining four variables.

As can be noticed from table (2), the correlation between GDP per worker and both, human capital per worker $(H / N)$ and human capital abundance $(h)$ is fairly strong at 0.6. Interestingly the choice of thresholds has a marginal impact on the correlation. However, the choice of threshold affects the correlation between GDP per worker and $(L / N)$. Not surprisingly, when we consider the higher threshold the negative association between GDP per worker and unskilled labor input drops. Finally, the correlation between capital output ratios and GDP per worker is quite low.

We calculate inter-industry TFP $\left(Z^{\frac{1-\alpha}{\alpha}}\right.$ in our calibration equation), by numerically approximating the definite integral under $Z$ using the quadratic interpolation method (Simpson rule). After taking logs of the levels, we back out $\ln B$, the homogeneous sector neutral component of TFP,

$$
\ln B=\ln y-\frac{1-\alpha}{\alpha} \ln \frac{K_{Y}}{Y}-\delta \ln \frac{L}{N}-(1-\delta) \ln \frac{H}{N}-\frac{1-\alpha}{\alpha} \ln Z
$$

By substituting (30) into $\ln (T F P)=\ln B+\frac{1-\alpha}{\alpha} \ln Z$ we construct aggregate TFP. ${ }^{14}$ Before gaps.

${ }^{14}$ This is exactly identical to calculating TFP as $\ln y-\frac{1-\alpha}{\alpha} \ln \frac{K_{Y}}{Y}+\delta \ln \frac{h}{1-h}-\ln \frac{H}{N}$. 
we begin discussing our own results, we compare our estimates of aggregate TFP with those of Hall and Jones (1999). This is instructive since the data is twenty years apart. Figure 3 indicates a strong linear relationship between our values for aggregate TFP and Hall and Jones' estimates. We find a correlation of 0.80 between the values predicted by our model and Hall and Jones' 1985 values when using completed secondary as the threshold for skilled labor. Using some tertiary education as a threshold, we found the correlation to be 0.82 . Thus, there was little change.

To undertake the variance decomposition exercise, we begin with equation (27) which implies that $y=T F P \times X$, where $X=\left[K_{Y} / Y\right]^{\frac{1-\alpha}{\alpha}}(L / N)^{\delta}(H / N)^{(1-\delta)}$, reflects a combined measure of factors of production. Taking logarithms, we can then write,

$$
\operatorname{var}[\ln (y)]=\operatorname{var}[\ln (X)]+\operatorname{var}[\ln (T F P)]+2 \operatorname{cov}[\ln (X), \ln (T F P)]
$$

Specifically, we calculate the contribution of each of these elements to the cross-country income dispersion. The covariance matrices in Table 3 presents the results of this decomposition exercise, with all variances and covariances listed relative to the variance of log GDP per worker. Panel A reports the results when using completed secondary education as the threshold, while panel B reports the results for some tertiary education. A trend that has developed in this literature, going back to Klenow and Rodriguez-Clare (1997), involves apportioning the covariance term equally to factors and TFP. Thus, the contribution of aggregate TFP is often reported as, ${ }^{15}$

$$
\frac{\operatorname{var}[\ln (T F P)]+\operatorname{cov}[\ln (X), \ln (T F P)]}{\operatorname{var}[\ln (y)]}
$$

Applying this rule, the numbers in panel A implies that aggregate TFP accounts for $92 \%$ of the differences in output per worker. Needless to mention, this is an extremely large share. The covariance term is also close to zero. However, in panel B, when we use some tertiary education, we get a different result. While TFP still accounts for the lion's share, it is now lower at $78.4 \%$. The reduction obviously reflects the fact that using some tertiary education introduces more variation in the human capital per worker (since capital-output ratios have not changed) and this comes at the cost of a reduced role for TFP.

To evaluate the role of inter-industry TFP we implement a second stage decomposition which involves,

$$
\operatorname{var}[\ln (T F P)]=\operatorname{var}[\ln (B)]+\operatorname{var}\left[\ln \left(Z^{\frac{1-\alpha}{\alpha}}\right)\right]+2 \operatorname{cov}\left[\ln (B), \ln \left(Z^{\frac{1-\alpha}{\alpha}}\right)\right]
$$

\footnotetext{
${ }^{15}$ If the covariance term is large, this apportioning can be misleading.
} 
The results of this decomposition are reported in Table 4. Like before, we present two sets of results based on different education thresholds. A quick inspection shows that the role of the human capital externality is higher when using some tertiary education. This is true for the same reason as in the aggregate TFP decomposition - the higher threshold allows for greater variation across countries. With only completed secondary as the threshold, the numbers from panel A indicate that inter-industry TFP is responsible for about $19.5 \%$ of aggregate TFP differences. Given that aggregate TFP itself accounts for ninety two percent of differences in GDP per worker, this suggests that inter-industry TFP accounts for about $18 \%$ of the variation in log output per worker. Obviously this number is not of an order of magnitude that questions the role of aggregate sector neutral differences. Nevertheless, to put it in perspective, it is larger than the share of factors of production as a whole. Panel B shows the effects of increasing the threshold level of education. In this case, inter-industry TFP accounts for $32 \%$ of aggregate TFP differences. This is almost double the share compared to the lower threshold. However, if we consider its role in GDP per worker differences, then another factor comes into play - aggregate TFP differences themselves already have a smaller role. We saw that aggregate TFP accounted for $77 \%$ of overall GDP per worker variations. Therefore, inter-industry TFP differences now account for $25 \%$ of differences in output per worker. Thus, its overall effect is tempered. To summarize, decomposition exercises in our model produces two effects of human capital. One is the direct factor accumulation effect and the other is the indirect TFP effect. If the measure of human capital is defined such that there is a large direct role, then it will also have a large role in explaining variances in TFP. However, given that TFP itself will have a smaller role to play, the total effect of the indirect role gets muted. ${ }^{16}$

\subsubsection{Sensitivity Analysis}

In this section we undertake two kinds of sensitivity analysis. One relates to the value of $\mu$ - the rate of growth of innate TFP from one industry to the next along the continuum. The second relates to changes in the share of skilled versus unskilled labor in the production function for intermediates, i.e. changes in $\delta$. A higher value of $\mu$ obviously reflects greater differences across sectors. Increasing $\mu$ would thus lead to a larger role of inter-industry TFP since countries have more to gain from being at $i$ close to 1 . Low values of $\mu$ would do the opposite and in the limit with $\mu=0$, the notion of appropriate technology and complementary human capital would disappear. To get a sense of the variation in interindustry TFP,

\footnotetext{
${ }^{16}$ Tables A-2 and A-3 in the appendix report the values of TFP and its components relative to US values.
} 
we repeat the exercise for $\mu=0.5$ and 1.5. In the former case, the ratio of innate TFP $\left(e^{\mu i}\right)$ for $i=0.9$ relative to $i=0.1$ is 1.5 while in the latter case it is 3.3 .

The results shown in Panel(A) in Table 5 suggest that, in this case inter-industry TFP, captured by $Z^{\frac{1-\alpha}{\alpha}}$, accounts for approximately $15 \%$ of the variation in aggregate TFP. This is only slightly lower than the case of $\mu=1$ where we found that it accounted for $19.5 \%$ of the variation. Panel $\mathrm{B}$ presents the results when $\mu$ is increased to 1.5. In this case, we find that share goes up to $24 \%$ - not a substantial increase. For the sake of brevity, we have only presented results with completed secondary as the threshold for skilled workers. When we increased the threshold to some tertiary education, the share was $27 \%$ for $\mu=0.5$ and $37 \%$ for $\mu=1.5$. Compared to the benchmark case of $\mu=1$, where the share was $32 \%$, these are not large changes. Finally, at the cost of repeating the obvious, changes in values of $\mu$ does not change the relative share of factors $(X)$ and aggregate TFP. This can be readily seen from equation (27).

Our next group of sensitivity tests, relate to changes in $\delta$ - the share of unskilled labor in the intermediate production function. As we already noted, Weil (2009) finds that share of unskilled labor in total wages varies from 0.5 for low income countries to 0.35 for high income countries. While we have adopted a middle of the road approach by setting $\delta=0.5$, it is instructive to examine how the results change with other values. We consider two variations, $\delta=1 / 3$, and $\delta=2 / 3$. The first reflects an economy where unskilled labor has a low share, while the latter reflects the opposite. We should note right away that changes in $\delta$ has no effect on the values of inter-industry TFP. This can be readily observed from equation (21). However, it will change the allocation between factors of production and aggregate TFP. To the extent that aggregate TFP values change, the share of inter-industry TFP will change. Instead of providing all the variances and covariances, we consolidate results by only displaying the variance shares in table (6). ${ }^{17}$ We present the variance share of aggregate TFP in GDP per worker and the variance share of inter-industry TFP in aggregate TFP. We also present the product of the two variance shares to get a sense of the variance share of inter-industry TFP in GDP per worker. In addition to $\delta=1 / 3$ and $2 / 3$, we repeat the results for $\delta=1 / 2$ for easier comparison.

Beginning with panel A, where the threshold is completed secondary education, we see that aggregate TFP explains virtually all of the dispersion in GDP per worker for the high value of $\delta$. Underlying these numbers is the fact that variation in TFP is now actually higher than the variation in GDP per worker, with a negative covariance between TFP and factors.

\footnotetext{
${ }^{17}$ The table reflects variance shares as described in equation (32).
} 
The negative covariance is enough to offset the high variance of TFP and bring its share down to $100 \%$. To understand why TFP now has such a large role to play, note the human capital term in equation $(27)$ is $(L / N)^{\delta}(H / N)^{1-\delta}$. With completed secondary education as the the threshold, the variation in $L / N$ is lower than the variation in $H / N$. Setting $\delta=2 / 3$ implies $L / N$ an even higher weight. Therefore whatever variation there was with $\delta=1 / 2$ in the factor accumulation terms, is now driven away. In Row 2 of table (6), variance share of inter-industry TFP relative to aggregate TFP increases as we increase $\delta$. We just noted that the value of interindustry TFP will not change with changes in delta. Therefore, if the variance of aggregate TFP increases we should actually expect the variance share of interindustry TFP to decrease. However, what these tables do not reveal is that the covariance between inter-industry TFP and and the sector neutral TFP component $(B)$ increases as we increase $\delta$. This is large enough to more than offset the decrease in the ratio of the variance of inter-industry TFP relative to aggregate TFP In panel B, where the threshold is higher, we see similar trends. While the role of aggregate TFP variations is lower, increases in $\delta$ lead to increases in the role of TFP. Once again the covariance between inter-industry TFP and $B$ is large enough to offset the reduced role of the former. Overall despite the large changes in factor shares, the role of inter-industry TFP does not change dramatically.

\subsubsection{Dispersion of Intermediate Production}

Since the model is based on the notion that productivity differences emerge based on the complementarity between human capital abundance and innate TFP, it naturally creates heterogeneity in the quantity of intermediate input produced across the different varieties. In human capital scarce countries, intermediate inputs along the lower values of the 0-1 index will have larger shares while the opposite is true for human capital abundant countries. The assumption of log normality in the externality function also creates a degree of asymmetry as discussed earlier. To visualize the distribution of intermediate industry shares, we group the continuum of industries in ten groups based on their position along the index. We then calculate each group's share in total GDP (see Appendix 1A). We plot the output distribution for two countries - Ghana, which has the lowest GDP per worker and USA, which has the highest. We present figures for both thresholds.

Figure 4 reflects the results when skilled labor is defined to include anyone who has completed secondary schooling. ${ }^{18}$ The pattern is more or less as expected for both countries.

\footnotetext{
${ }^{18}$ Note that the histogram reflects shares relative to GDP. Since intermediate inputs have a combined share of $2 / 3$ in final production, the sum of the individual bars will add up to $66 \%$.
} 
For Ghana, the peak industry is at the lower end of the continuum. For the US, clearly it is the opposite with the top ten percent of the continuum seeing the largest share. From the charts one can also see that Ghana actually has a more spread out industrial mix producing across the spectrum. For the US, we see that there is literally no production in the range, $i=0$ to 0.1 . This is because the US has a very high value of human capital abundance $(h)$ at 0.802 . As a result, there is little to be gained from producing in the lower end of the spectrum. On the other hand, since Ghana has a respectable share of the population that has completed secondary education (almost twenty percent), it makes sense for them to produce a little bit at industries at the highest end of the continuum. In addition to the charts, we also calculated a crude Herfindahl style index, $\sum_{i}^{10} s_{i}^{2}$ where $s_{i}$ is the share of output of each firm in total intermediate production. A high value means that production is concentrated to a few firms a low share implies that production is spread out across firms. We approximate the number of firms into ten groups based on ten equal intervals along the index. ${ }^{19}$ With secondary education as the threshold, both for US and Ghana, the values were 0.17 and 0.13 respectively. In other words, the index reflects the diversification we see for both countries in the charts. Since these are the two extreme cases, other countries fall into this narrow range.

Figure (5) reflects the distribution of industries when we change the threshold to some tertiary education. The slight increase in threshold has dramatic effects on the distribution. We now see that Ghana specializes in the low end while the US still continues to exhibit a fairly diversified structure. This reflects the fact that Ghana's higher education attainment rates are very low $(h=0.028)$ while the US has much higher rates of attainment $(h=0.370)$. The same crude Herfindahl index now returns a value of 0.7 for Ghana and 0.12 for the US An obvious question that arises is which of these distributions have any resemblance to reality. Imbs and Wacziarg (2003) documents high levels of concentration in sectors at low levels of income with a declining concentration as income rises. However, they find evidence that there is also an increase in concentration once one reaches high enough levels of income per capita. Depending on the data set, this turn takes place at roughly $\$ 7000-\$ 9000$. Clearly, using completed secondary as a threshold does not provide any such pattern. Using some tertiary education provides some support for the initial increasing diversification but not the subsequent concentration. Imbs and Wacziarg themselves tie down the U-shaped behavior to the interaction of economic growth and international trade. With increasing aggregate

\footnotetext{
${ }^{19}$ In reality, the number of firms is of mass 1 . Also, note that the number of firms is the same for all countries.
} 
productivity, there is greater diversification while increasing trade leads to greater specialization. Our structure provides a link between human capital and aggregate productivity and thus covers the first part of their argument. ${ }^{20}$ However, this is at best, suggestive, and in future work, this is something that certainly deserves to be explored further.

\section{Conclusions}

In this paper, our aim was to introduce a structure that captured the notion of appropriate technology in the context of human capital endowments and relate that to recent advances in the development accounting literature. The quantitative exercises suggest that such complementarity between technology and human capital may account for eighteen to twenty five percent of the variation in GDP per worker across the sample. Sensitivity analysis with respect to labor share and innate TFP differences across industries do not seem to have a large effect on the overall result. What is crucial however is the definition of the threshold. The fact that changing the threshold can change the role of appropriate technology, suggests that an important next step is to consider multiple sectors of the economy. For example, one can think of one sector that is skill intensive by nature and another sector that is not. Needless to mention this would be closer to reality. One might even consider three levels of skills - basic literacy, completed schooling, and tertiary education and three sectors such as agriculture, industry and services. Of course with more types of skills and more industries comes added modeling complications, and more assumptions about parameter values. Therefore, as a first step, to introduce the model we have consciously stayed away from these extensions. Another extension that the model natural lends itself to, is the analysis of international trade. The fact that there is heterogeneous distribution of productivity which is tied to human capital endowments means that the model is ripe for application to international trade along the lines of Dornbusch, Fischer, and Samuelson (1977) and the literature that has developed since.

\footnotetext{
${ }^{20}$ There are of course other well established reasons for sectoral diversification during development. Most of these are related to the ability to hedge against risk. See for example, Saint-Paul (1992) and Acemoglu and Zilibotti (1997).
} 


\section{References}

Acemoglu, D. and Zilibotti, F. 1997. Was Prometheus unbound by chance? Risk, diversification, and growth Journal of Political Economy. vol.105(4), pages 709-751.

Acemoglu, D. and Zilibotti, F. 2001. Productivity Differences. Quarterly Journal of Economics. 116(2): 563-606.

Armenter, R. and Lahiri, A. 2011. Accounting for Development through Investment Prices. Journal of Monetary Economics, forthcoming.

Atkinson, A. and Stiglitz, J. 1969. A New View of Technological Change. Economic Journal. Royal Economic Society, vol. 79(315), pages 573-78.

Barro, R. and Lee, J. 2001. International Data on Educational Attainment: Updates and Implications, Oxford University Press. vol. 53(3):541-63.

Basu, S. and Weil, D. 1998. Appropriate Technology and Growth. Quarterly Journal of Economics. 113(4): 1025-54.

Caselli, F. 2005. Accounting for Cross-Country Income Differences. in: Philippe Aghion and Steven Durlauf (ed.), Handbook of Economic Growth,Elsevier. edition 1, volume 1: pages $679-741$.

Caselli, F. and Coleman, W.J. 2006. The World Technology Frontier. American Economic Review. vol. 96(3):499-522.

Chanda, A. and Dalgaard, C-J. 2007. Dual Economies and International Total Factor Productivity Differences: Channeling the Impact from Institutions, Trade, and Geography. Economica. London School of Economics and Political Science, vol.75(300), pages 629-661.

Chmelarova, V. and Papageorgiou, C. 2005. Nonlinearities in Capital-Skill Complementarity. Journal of Economic Growth. Springer, vol.10(1), pages 55-86.

Dornbusch, R., Fischer, S., and Samuelson, P. 1977. Comparative Advantage, Trade, and Payments in a Ricardian Model with a Continuum of Goods. American Economic Review. American Economic Association, vol. 67(5), pages 823-39. 
Erosa, A., Koreshkova, T. and Restuccia, D. 2007. How Important is Human Capital? A Quantitative Theory Assessment of World Income Inequality. Review of Economic Studies. Wiley Blackwell, vol. 77(4), pages 1421-1449.

Hall, R.E. and Jones, C.I. 1999. Why Do Some Countries Produce So Much More Output Per Worker Than Others? Quarterly Journal Of Economics. 114: 83-116.

Heston, Alan, Summers, R., and Aten, B., 2011, Penn World Table Version 7.0, Center for International Comparisons of Production, Income and Prices at the University of Pennsylvania.

Hsieh, C. and Klenow, P. 2007. Misallocation and Manufacturing TFP in China and India. NBER Working Papers 13290, National Bureau of Economic Research, Inc.

Hsieh, C. and Klenow, P. 2010. Development Accounting. American Economic Journal: Macroeconomics. 2:1, 207-223.

Imbs, J. and Wacziarg, R. 2003. Stages of Diversification. American Economic Review. American Economic Association, vol. 93(1), pages 63-86.

Jones, B. 2011. The Human Capital Stock: A Generalized Approach. (NBER Working Paper no.17487).

Klenow, P. and Rodriguez-Clare, A. 1997. The Neoclassical Revival in Growth Economics: Has It Gone Too Far? in Bernanke, B. and Rotemberg, J. (eds). NBER Macroeconomics Annual, Cambridge, MA: MIT Press. 73-103.

Mankiw, G., Romer, D. and Weil, D. 1992. A Contribution to the Empirics of Economic Growth. The Quarterly Journal of Economics, MIT Press. vol. 107(2); 407-37.

Restuccia, D. and Rogerson, R. 2008. Policy Distortions and Aggregate Productivity with Heterogeneous Plants. Review of Economic Dynamics. Elsevier for the Society for Economic Dynamics, vol. 11(4), pages 707-720.

Saint-Paul, G. 1992. Technological Choice, Financial Markets and Economic Development. European Economic Review., April 1992, 36(4), pp. 763-81.

Schoellman, T 2012. Education Quality and Development Accounting. Review of Economic Studies January 2012, Vol. 79 (1), 388-417. 
Vollrath, D. 2009. How important are dual economy effects for aggregate productivity?. Journal of Development Economics. Elsevier, vol.88(2), pages 325-334. 


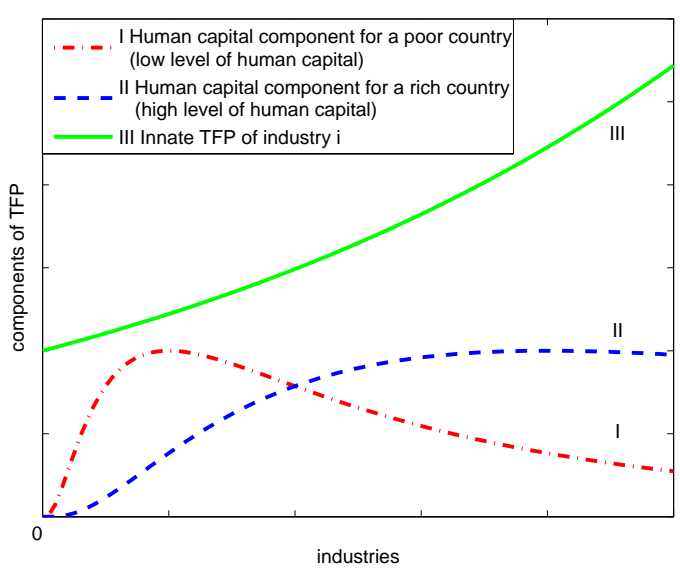

(A)

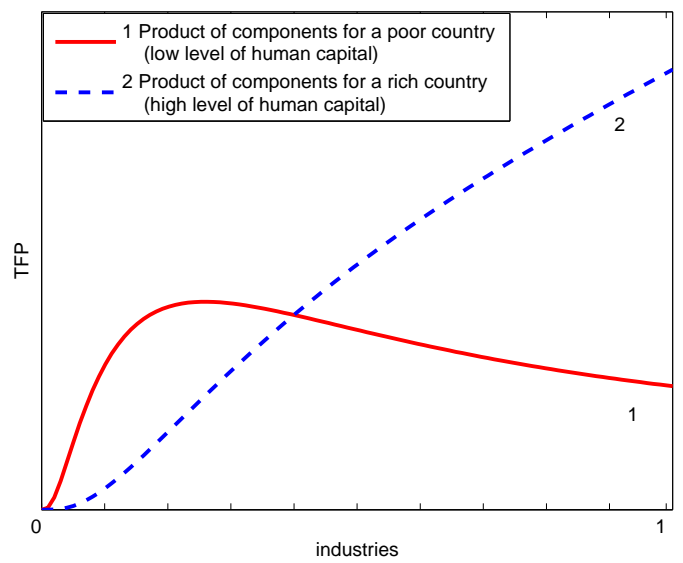

(B)

Figure 1: Distribution of the Components of TFP across Industries.

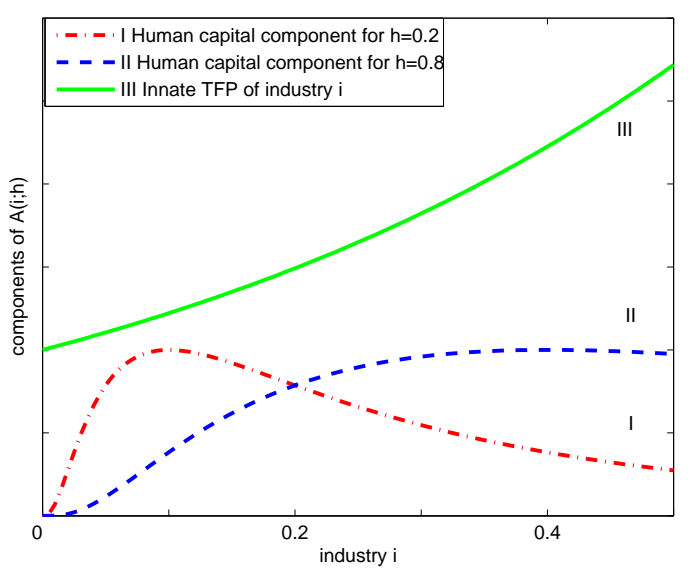

(A)

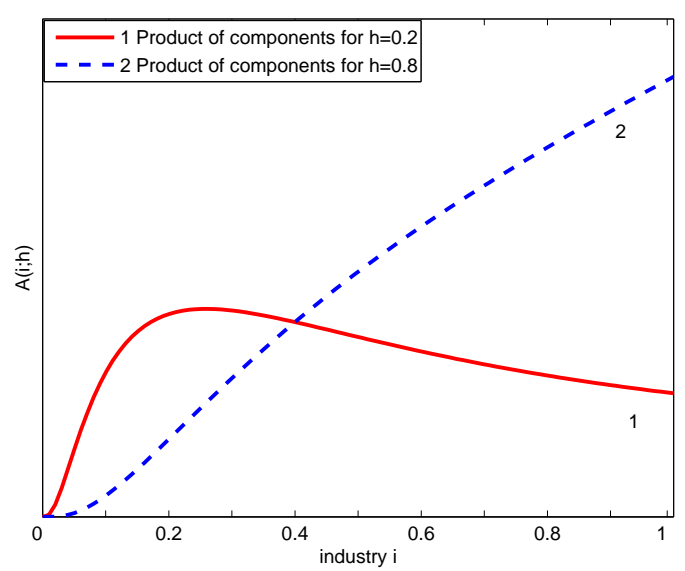

(B)

Figure 2: Distribution of A(i,h) across Industries with Low and High Human Capital. 


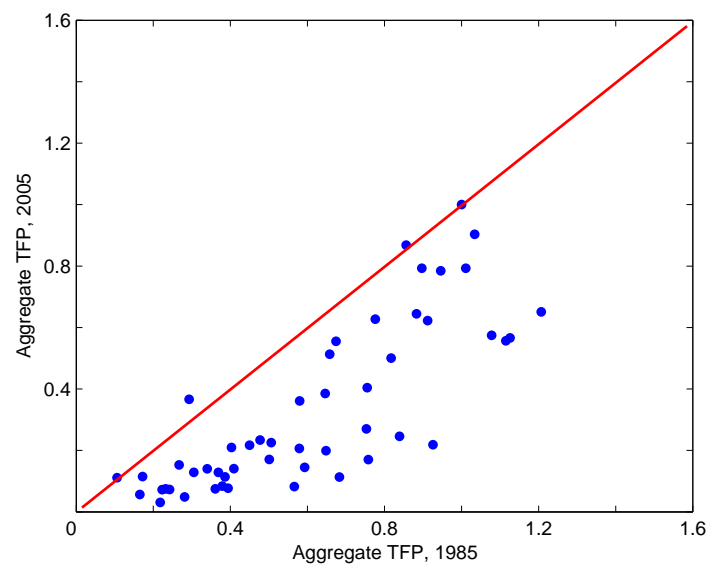

Figure 3: Comparison of 2005 TFP values with Hall and Jones (1999) estimates 


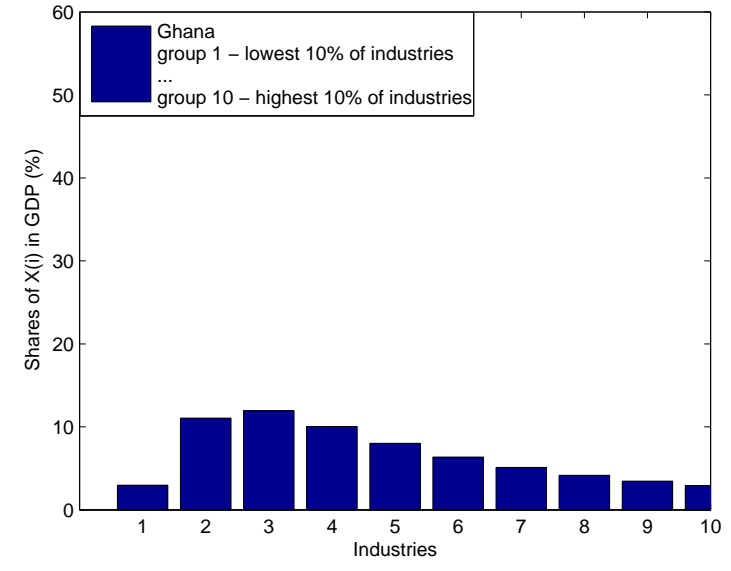

(A) Ghana

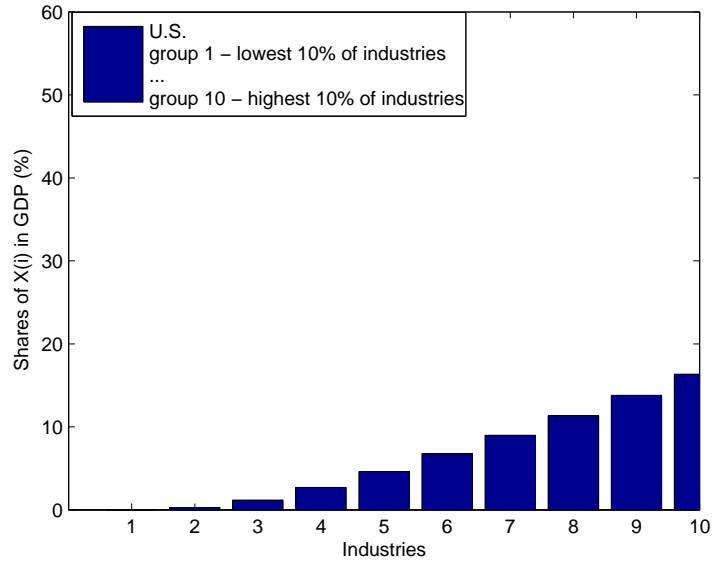

(B) US

Figure 4: Shares of industries in GDP (\%). Skilled labor threshold: completed secondary education.

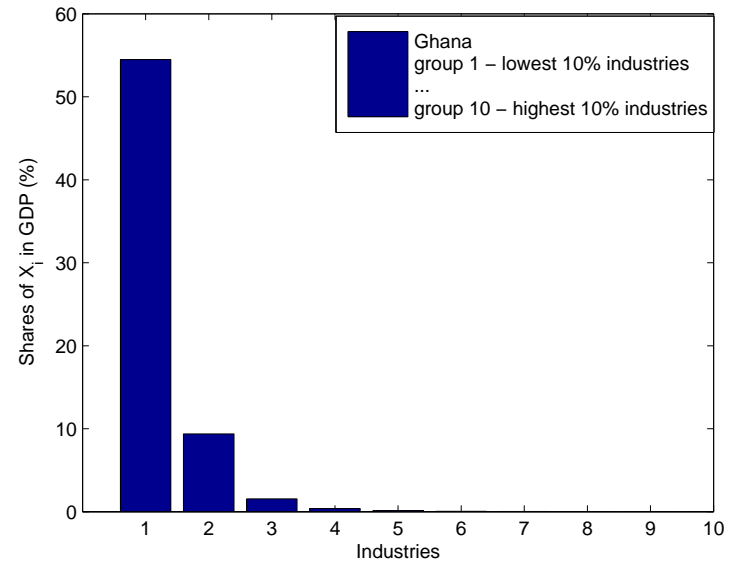

(A) Ghana

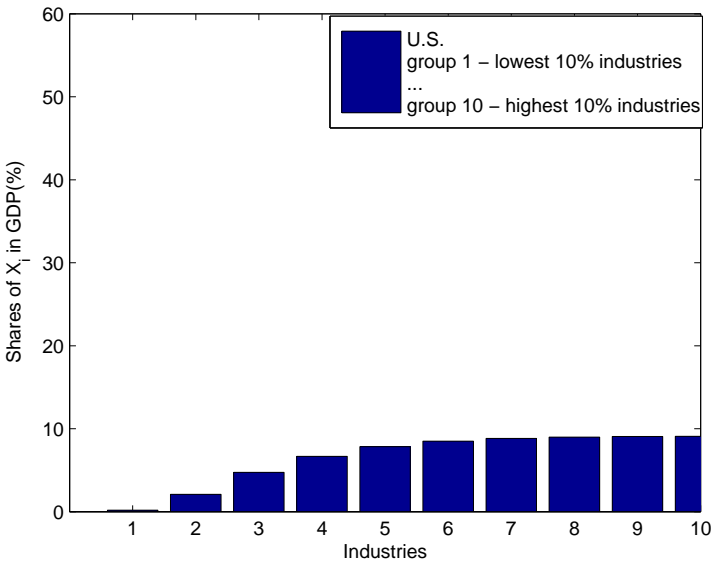

(B) US

Figure 5: Shares of industries in GDP (\%). Skilled labor threshold: some tertiary education. 
Table 1: Summary Statistics of the Data

\begin{tabular}{|c|cccc|}
\hline \hline Variable & Mean & Std.Dev & Min & Max \\
\hline \hline GDP per Worker $(y)$ & 20187 & 15862 & 1708 & 53244 \\
Capital Output Ratio $(K / Y)$ & 2.52 & 0.60 & 1.43 & 3.73 \\
Summary Statistics when & Threshold is & Completed Secondary Education & \\
Unskilled Labor Input $(L / N)$ & 3.50 & 1.00 & 1.00 & 10.12 \\
Skilled Labor Input $(H / N)$ & 0.44 & 0.20 & 0.07 & 1.00 \\
Human Capital Abundance $(h)$ & 0.37 & 0.19 & 0.03 & 0.80 \\
Summary Statistics when & Threshold is Some Tertiary Education & \\
Unskilled Labor Input $(L / N)$ & 1.39 & 0.97 & 0.66 & 6.96 \\
Skilled Labor Input $(H / N)$ & 0.31 & 0.20 & 0.06 & 1.00 \\
Human Capital Abundance $(h)$ & 0.13 & 0.08 & 0.02 & 0.37 \\
\hline
\end{tabular}

and $h$ the values are actual magnitudes whereas the labor input measures are relative to the US.

Note that for $(L / N)$ when using completed secondary as a threshold, the lowest value of 1 corresponds to the US and the highest value of 10.12 corresponds to Botswana.

Table 2: Correlations with GDP per Worker (2005)

\begin{tabular}{|c|c|}
\hline \hline Variable & Correlation with GDP per worker \\
\hline Capital Output Ratio $(K / Y)$ & 0.21 \\
Completed Secondary: & -0.43 \\
Unskilled Labor Input $(L / N)$ & 0.61 \\
Skilled Labor Input $(H / N)$ & 0.64 \\
Human Capital Abundance $(h)$ & \\
Some Tertiary: & -0.21 \\
Unskilled Labor Input $(L / N)$ & 0.60 \\
Skilled Labor Input $(H / N)$ & 0.66 \\
Human Capital Abundance $(h)$ & \\
\hline
\end{tabular}

Note: Cross-section of 51 countries for the year 2005. 
Table 3: Variance Decomposition of Output per Worker

\begin{tabular}{|c|c|c|c|}
\hline \multicolumn{4}{|c|}{ A: Skilled Labor: Completed Secondary Education and Above } \\
\hline Variable & $\ln (y)$ & $\ln ($ factors $)$ & $\ln (T F P)$ \\
\hline $\ln (y)$ & 0.862 & & \\
\hline $\ln ($ factors $)$ & 0.070 & 0.091 & \\
\hline $\ln (T F P)$ & 0.791 & -0.020 & 0.812 \\
\hline \multicolumn{4}{|c|}{ B: Skilled Labor: Some Tertiary Education and Above } \\
\hline Variable & $\ln (y)$ & $\ln ($ factors $)$ & $\ln (T F P)$ \\
\hline $\ln (y)$ & 0.862 & & \\
\hline $\ln ($ factors $)$ & 0.185 & 0.170 & \\
\hline $\ln (T F P)$ & 0.677 & 0.014 & 0.662 \\
\hline
\end{tabular}

Table 4: Variance Decomposition of Total Factor Productivity A: Skilled Labor: Completed Secondary Education and Above

\begin{tabular}{|c|c|c|c|}
\hline Variable & $\ln (T F P)$ & $\ln (B)$ & $\ln \left(Z^{\frac{1-\alpha}{\alpha}}\right)$ \\
\hline $\ln (T F P)$ & 0.812 & & \\
$\ln (B)$ & 0.652 & 0.626 & 0.133 \\
$\ln \left(Z^{\frac{1-\alpha}{\alpha}}\right)$ & 0.159 & 0.025 & \\
\hline
\end{tabular}

B: Skilled Labor: Some Tertiary Education and Above

\begin{tabular}{|c|c|c|c|}
\hline Variable & $\ln (T F P)$ & $\ln (B)$ & $\ln \left(Z^{\frac{1-\alpha}{\alpha}}\right)$ \\
\hline $\ln (T F P)$ & 0.662 & & \\
$\ln (B)$ & 0.452 & 0.504 & \\
$\ln \left(Z^{\frac{1-\alpha}{\alpha}}\right)$ & 0.210 & -0.051 & 0.262 \\
\hline
\end{tabular}


Table 5: Variance Decomposition of Aggregate TFP - Sensitivity analysis with respect to changes in $\mu$.

\begin{tabular}{|c|c|c|c|}
\hline \multicolumn{4}{|c|}{ Skilled Labor: Completed Secondary and Above } \\
\hline \multicolumn{4}{|c|}{ A) $\mu=0.5$} \\
\hline Variable & $\ln (T F P)$ & $\ln (B)$ & $\ln \left(Z^{\frac{1-\alpha}{\alpha}}\right)$ \\
\hline $\ln (T F P)$ & 0.812 & 0.650 & \\
$\ln (B)$ & 0.687 & 0.037 & 0.086 \\
$\ln \left(Z^{\frac{1-\alpha}{\alpha}}\right)$ & 0.124 & $\operatorname{Bn}\left(Z^{\frac{1-\alpha}{\alpha}}\right)$ \\
\hline \multicolumn{5}{|c|}{$\mu=1.5$} \\
\hline Variable & $\ln (T F P)$ & $\ln (B)$ & \\
\hline $\ln (T F P)$ & 0.812 & 0.616 & 0.192 \\
$\ln (B)$ & 0.617 & 0.001 & \\
$\ln \left(Z^{\frac{1-\alpha}{\alpha}}\right)$ & 0.194 &
\end{tabular}

Table 6: Variance Decomposition of TFP - Sensitivity analysis with respect to changes in labor shares $(\delta)$.

\begin{tabular}{|c|c|c|c|}
\hline \multicolumn{4}{|c|}{ A) Skilled Labor: Completed Secondary Education and Above } \\
\hline & $\delta=\frac{1}{3}$ & $\delta=\frac{1}{2}$ & $\delta=\frac{2}{3}$ \\
\hline 1) Share of Aggregate TFP $(A)$ in $y$ & 0.81 & 0.92 & 1.00 \\
\hline 2)Share of Inter Industry TFP $\left(\ln \left(Z^{\frac{1-\alpha}{\alpha}}\right)\right)$ in Aggregate TFP $(A)$ & 0.16 & 0.20 & 0.21 \\
\hline 3)Share of Inter- Industry TFP in $y$ & 0.13 & 0.18 & 0.21 \\
\hline \multicolumn{4}{|c|}{ B) Skilled Labor: Some Tertiary Education or Above } \\
\hline & $\delta=\frac{1}{3}$ & $\delta=\frac{1}{2}$ & $\delta=\frac{2}{3}$ \\
\hline 4) Share of Aggregate TFP $(A)$ in $y$ & 0.66 & 0.79 & 0.88 \\
\hline 5) Share of Inter Industry TFP $\left(\ln \left(Z^{\frac{1-\alpha}{\alpha}}\right)\right)$ in Aggregate TFP $(A)$ & 0.24 & 0.32 & 0.35 \\
\hline 6) Share of Inter- Industry TFP in $y$ & 0.16 & 0.25 & 0.31 \\
\hline
\end{tabular}

* Note: Entries in 1) \& 4) and 2) \& 5) are based on equations (31) and (33) respectively.

Covariances are assigned equally to the two variance terms. Results for $\delta=1 / 2$ reflect the numbers already displayed in Tables (3) and (4). 


\section{Appendix}

\section{Share of industry $i$ in GDP:}

From (1) and (2) we calculate the share of variety $i$ in GDP:

$$
\frac{p_{i} X_{i}}{Y}=\alpha \frac{p_{i} X_{i}}{\int_{0}^{1} p_{i} X_{i} d i}=\alpha \frac{X_{i}^{\alpha}}{\int_{0}^{1} X_{i}^{\alpha} d i}
$$

$X_{i}$ is given by the first order condition from the intermediate goods sector:

$$
X_{i}=\left[\frac{1}{\alpha^{2}} \frac{1}{A(i, h)} \frac{\delta^{-\delta}}{(1-\delta)^{1-\delta}} w_{L_{i}}^{\delta} w_{H_{i}}^{1-\delta}\right]^{\frac{1}{\alpha-1}} K_{Y}
$$

After substituting for $\frac{\delta^{-\delta}}{(1-\delta)^{1-\delta}} w_{L_{i}}^{\delta} w_{H_{i}}^{1-\delta}$, we get:

$$
X_{i}^{\alpha}=L^{\alpha \delta} H^{\alpha(1-\delta)} A(i, h)^{\frac{\alpha}{1-\alpha}}\left[\int_{0}^{1} A(i, h)^{\frac{\alpha}{1-\alpha}} d i\right]^{-\alpha}=L^{\alpha \delta} H^{\alpha(1-\delta)}\left[\int_{0}^{1} A(i, h)^{\frac{\alpha}{1-\alpha}} d i\right]^{1-\alpha}
$$

Substituting (35) into (34), we have:

$$
\begin{gathered}
\alpha \frac{p_{i} X_{i}}{\int_{0}^{1} p_{i} X_{i} d i}=\alpha \frac{A(i, h)^{\frac{\alpha}{1-\alpha}}}{\int_{0}^{1} A(i, h)^{\frac{\alpha}{1-\alpha}} d i} \\
=\alpha \frac{A(i, h)^{\frac{\alpha}{1-\alpha}}}{B^{\frac{\alpha}{1-\alpha}} Z}=\alpha \frac{B^{\frac{\alpha}{1-\alpha}}\left[e^{\mu i} e^{\frac{-1}{2}\left(\ln \frac{h}{i}\right)^{2}}\right]^{\frac{\alpha}{1-\alpha}}}{B^{\frac{\alpha}{1-\alpha}} Z}=\alpha \frac{\left[e^{\mu i} e^{\frac{-1}{2}\left(\ln \frac{h}{i}\right)^{2}}\right]^{\frac{\alpha}{1-\alpha}}}{Z}
\end{gathered}
$$

Thus, the share of variety $i$ in GDP is given by:

$$
\frac{p_{i} X_{i}}{Y}=\alpha \frac{\left[e^{\mu i} e^{\frac{-1}{2}\left(\ln \frac{h}{i}\right)^{2}}\right]^{\frac{\alpha}{1-\alpha}}}{Z}
$$

Next, we calculate the share of the lowest $10 \%$ of varieties in GDP:

$$
\frac{\int_{0}^{0.1} p_{i} X_{i} d i}{Y}=\alpha \frac{\int_{0}^{0.1}\left[e^{\mu i} e^{\frac{-1}{2}\left(\ln \frac{h}{i}\right)^{2}}\right]^{\frac{\alpha}{1-\alpha}} d i}{\int_{0}^{1}\left[e^{\mu i} e^{\frac{-1}{2}\left(\ln \frac{h}{i}\right)^{2}}\right]^{\frac{\alpha}{1-\alpha}} d i}
$$

The share of the highest $10 \%$ of varieties in GDP is given by:

$$
\frac{\int_{0.9}^{1} p_{i} X_{i} d i}{Y}=\alpha \frac{\int_{0.9}^{1}\left[e^{\mu i} e^{\frac{-1}{2}\left(\ln \frac{h}{i}\right)^{2}}\right]^{\frac{\alpha}{1-\alpha}} d i}{\int_{0}^{1}\left[e^{\mu i} e^{\frac{-1}{2}\left(\ln \frac{h}{i}\right)^{2}}\right]^{\frac{\alpha}{1-\alpha}} d i}
$$


Table A-1: Data: $y=$ GDP per worker; $K_{Y} / Y=$ capital output ratio; $(H / N)_{j}=$ skilled labor input per worker ; $h_{j}=$ human capital abundance. $j=s, t$, where $s$ denotes completed secondary education, and $t$ denotes some tertiary. All values are relative to US

\begin{tabular}{|c|c|c|c|c|c|c|c|}
\hline Country & Country code & $y$ & $\left(\frac{K_{Y}}{Y}\right)^{\frac{1-\alpha}{\alpha}}$ & $\left(\frac{H}{N}\right)_{s}$ & $h_{s}=\frac{H_{s}}{H_{s}+L_{s}}$ & $\left(\frac{H}{N}\right)_{t}$ & $h_{t}=\frac{H_{t}}{H_{t}+L_{t}}$ \\
\hline Argentina & $\mathrm{ARG}$ & 0.257 & 1.035 & 0.392 & 0.356 & 0.195 & 0.190 \\
\hline Australia & AUS & 0.900 & 1.034 & 0.651 & 0.786 & 0.500 & 0.716 \\
\hline Bolivia & BOL & 0.103 & 0.802 & 0.522 & 0.652 & 0.256 & 0.338 \\
\hline Botswana & BWA & 0.292 & 1.241 & 0.409 & 0.176 & 0.122 & 0.046 \\
\hline Brazil & BRA & 0.220 & 1.011 & 0.352 & 0.293 & 0.176 & 0.139 \\
\hline Canada & $\mathrm{CAN}$ & 0.834 & 0.977 & 0.690 & 0.852 & 0.626 & 0.942 \\
\hline Chile & CHL & 0.275 & 0.951 & 0.647 & 0.585 & 0.520 & 0.452 \\
\hline China & $\mathrm{CHN}$ & 0.112 & 1.066 & 0.414 & 0.551 & 0.097 & 0.150 \\
\hline Colombia & COL & 0.165 & 0.962 & 0.383 & 0.372 & 0.192 & 0.167 \\
\hline Costa Rica & CRI & 0.254 & 0.952 & 0.353 & 0.331 & 0.291 & 0.318 \\
\hline Cyprus & CYP & 0.522 & 1.042 & 0.600 & 0.579 & 0.465 & 0.447 \\
\hline Dominican Republic & DOM & 0.217 & 0.910 & 0.269 & 0.272 & 0.280 & 0.372 \\
\hline Ecuador & ECU & 0.165 & 1.157 & 0.402 & 0.367 & 0.344 & 0.354 \\
\hline El Salvador & SLV & 0.148 & 0.872 & 0.262 & 0.272 & 0.189 & 0.240 \\
\hline France & FRA & 0.739 & 1.051 & 0.585 & 0.591 & 0.377 & 0.376 \\
\hline Germany & DEU & 0.691 & 1.129 & 0.644 & 0.794 & 0.290 & 0.403 \\
\hline Ghana & GHA & 0.032 & 1.113 & 0.207 & 0.208 & 0.062 & 0.076 \\
\hline Greece & GRC & 0.541 & 1.106 & 0.424 & 0.606 & 0.291 & 0.555 \\
\hline Guatemala & GTM & 0.180 & 0.932 & 0.110 & 0.109 & 0.061 & 0.073 \\
\hline Honduras & HND & 0.102 & 1.062 & 0.237 & 0.152 & 0.162 & 0.114 \\
\hline Hong Kong & $\mathrm{HKG}$ & 0.712 & 1.227 & 0.492 & 0.597 & 0.250 & 0.345 \\
\hline Hungary & HUN & 0.368 & 1.025 & 0.530 & 0.678 & 0.200 & 0.303 \\
\hline India & IND & 0.070 & 0.896 & 0.066 & 0.079 & 0.085 & 0.146 \\
\hline Indonesia & IDN & 0.093 & 1.109 & 0.245 & 0.196 & 0.069 & 0.051 \\
\hline Israel & ISR & 0.621 & 1.086 & 0.562 & 0.619 & 0.550 & 0.758 \\
\hline Italy & ITA & 0.652 & 1.174 & 0.341 & 0.493 & 0.122 & 0.236 \\
\hline Jamaica & JAM & 0.254 & 1.222 & 0.752 & 0.291 & 0.672 & 0.145 \\
\hline Japan & JPN & 0.712 & 1.293 & 0.642 & 0.742 & 0.567 & 0.775 \\
\hline Kenya & KEN & 0.039 & 0.829 & 0.070 & 0.035 & 0.094 & 0.066 \\
\hline Malaysia & MYS & 0.305 & 1.114 & 0.545 & 0.539 & 0.265 & 0.261 \\
\hline Mexico & MEX & 0.323 & 0.970 & 0.463 & 0.338 & 0.394 & 0.306 \\
\hline Netherlands & NLD & 0.885 & 0.995 & 0.598 & 0.662 & 0.404 & 0.489 \\
\hline Nicaragua & NIC & 0.061 & 1.284 & 0.290 & 0.335 & 0.269 & 0.385 \\
\hline Pakistan & PAK & 0.069 & 0.949 & 0.249 & 0.303 & 0.108 & 0.148 \\
\hline Panama & PAN & 0.206 & 0.946 & 0.621 & 0.490 & 0.538 & 0.413 \\
\hline Paraguay & PRY & 0.103 & 1.066 & 0.334 & 0.317 & 0.069 & 0.064 \\
\hline Peru & PER & 0.159 & 1.048 & 0.470 & 0.545 & 0.347 & 0.456 \\
\hline Philippines & PHL & 0.078 & 0.996 & 0.451 & 0.518 & 0.446 & 0.630 \\
\hline Portugal & PRT & 0.452 & 1.206 & 0.237 & 0.263 & 0.179 & 0.243 \\
\hline Singapore & SGP & 0.999 & 1.184 & 0.454 & 0.351 & 0.443 & 0.387 \\
\hline South Korea & KOR & 0.528 & 1.239 & 0.851 & 0.850 & 0.731 & 0.680 \\
\hline Sri Lanka & LKA & 0.080 & 1.043 & 0.602 & 0.749 & 0.254 & 0.317 \\
\hline Sweden & SWE & 0.790 & 0.992 & 0.760 & 0.871 & 0.437 & 0.513 \\
\hline Switzerland & $\mathrm{CHE}$ & 0.872 & 1.272 & 0.543 & 0.645 & 0.308 & 0.381 \\
\hline Taiwan & TWN & 0.622 & 0.993 & 0.618 & 0.758 & 0.502 & 0.724 \\
\hline Thailand & THA & 0.175 & 1.221 & 0.278 & 0.253 & 0.225 & 0.252 \\
\hline Tunisia & TUN & 0.135 & 1.297 & 0.245 & 0.282 & 0.157 & 0.225 \\
\hline UK & GBR & 0.793 & 0.913 & 0.297 & 0.285 & 0.376 & 0.503 \\
\hline Uruguay & URY & 0.208 & 0.943 & 0.256 & 0.235 & 0.164 & 0.185 \\
\hline USA & USA & 1.000 & 1.000 & 1.000 & 1.000 & 1.000 & 1.000 \\
\hline Venezuela & VEN & 0.224 & 1.027 & 0.215 & 0.240 & 0.261 & 0.403 \\
\hline
\end{tabular}


Table A-2: TFP and its components (Skilled labor threshold: completed secondary education) $\quad B=$ sector neutral TFP, $Z^{\frac{1-\alpha}{\alpha}}=$ inter-industry TFP. All values are relative to U.S

\begin{tabular}{|c|c|c|c|c|}
\hline Country & Country code & $B$ & $Z^{\frac{1-\alpha}{\alpha}}$ & $T F P=B Z^{\frac{1-\alpha}{\alpha}}$ \\
\hline Argentina & $\mathrm{ARG}$ & 0.257 & 0.774 & 0.199 \\
\hline Australia & AUS & 0.862 & 1.007 & 0.868 \\
\hline Bolivia & BOL & 0.131 & 0.982 & 0.129 \\
\hline Botswana & BWA & 0.239 & 0.480 & 0.115 \\
\hline Brazil & BRA & 0.247 & 0.688 & 0.170 \\
\hline Canada & CAN & 0.895 & 1.010 & 0.903 \\
\hline Chile & CHL & 0.219 & 0.957 & 0.209 \\
\hline China & $\mathrm{CHN}$ & 0.119 & 0.940 & 0.111 \\
\hline Colombia & $\mathrm{COL}$ & 0.183 & 0.793 & 0.145 \\
\hline Costa Rica & CRI & 0.304 & 0.742 & 0.226 \\
\hline Cyprus & CYP & 0.404 & 0.954 & 0.385 \\
\hline Dominican Republic & DOM & 0.357 & 0.656 & 0.234 \\
\hline Ecuador & $\mathrm{ECU}$ & 0.144 & 0.787 & 0.114 \\
\hline El Salvador & SLV & 0.260 & 0.656 & 0.170 \\
\hline France & FRA & 0.590 & 0.959 & 0.566 \\
\hline Germany & $\mathrm{DEU}$ & 0.618 & 1.008 & 0.623 \\
\hline Ghana & GHA & 0.057 & 0.544 & 0.031 \\
\hline Greece & GRC & 0.575 & 0.966 & 0.555 \\
\hline Guatemala & GTM & 0.796 & 0.339 & 0.270 \\
\hline Honduras & HND & 0.174 & 0.432 & 0.075 \\
\hline Hong Kong & $\mathrm{HKG}$ & 0.579 & 0.962 & 0.557 \\
\hline Hungary & HUN & 0.371 & 0.989 & 0.367 \\
\hline India & IND & 0.563 & 0.271 & 0.153 \\
\hline Indonesia & IDN & 0.140 & 0.520 & 0.073 \\
\hline Israel & ISR & 0.515 & 0.971 & 0.500 \\
\hline Italy & ITA & 0.720 & 0.904 & 0.651 \\
\hline Jamaica & JAM & 0.110 & 0.685 & 0.075 \\
\hline Japan & JPN & 0.512 & 1.002 & 0.513 \\
\hline Kenya & KEN & 0.349 & 0.162 & 0.057 \\
\hline Malaysia & MYS & 0.233 & 0.933 & 0.217 \\
\hline Mexico & MEX & 0.291 & 0.752 & 0.218 \\
\hline Netherlands & NLD & 0.797 & 0.985 & 0.785 \\
\hline Nicaragua & NIC & 0.065 & 0.747 & 0.049 \\
\hline Pakistan & PAK & 0.117 & 0.704 & 0.082 \\
\hline Panama & PAN & 0.155 & 0.902 & 0.140 \\
\hline Paraguay & PRY & 0.116 & 0.723 & 0.084 \\
\hline Peru & PER & 0.150 & 0.937 & 0.141 \\
\hline Philippines & PHL & 0.079 & 0.921 & 0.072 \\
\hline Portugal & PRT & 0.630 & 0.641 & 0.404 \\
\hline Singapore & SGP & 0.748 & 0.768 & 0.575 \\
\hline South Korea & KOR & 0.358 & 1.010 & 0.361 \\
\hline Sri Lanka & LKA & 0.077 & 1.003 & 0.077 \\
\hline Sweden & SWE & 0.785 & 1.010 & 0.793 \\
\hline Switzerland & $\mathrm{CHE}$ & 0.658 & 0.980 & 0.645 \\
\hline Taiwan & TWN & 0.625 & 1.004 & 0.627 \\
\hline Thailand & THA & 0.206 & 0.624 & 0.129 \\
\hline Tunisia & TUN & 0.169 & 0.671 & 0.113 \\
\hline UK & GBR & 1.172 & 0.677 & 0.793 \\
\hline Uruguay & URY & 0.348 & 0.593 & 0.207 \\
\hline USA & USA & 1.000 & 1.000 & 1.000 \\
\hline Venezuela & VEN & 0.408 & 0.603 & 0.246 \\
\hline
\end{tabular}


Table A-3: TFP and its components (Skilled labor threshold: some tertiary education) $B=$ sector neutral TFP, $Z^{\frac{1-\alpha}{\alpha}}=$ inter-industry TFP. All values are relative to US

\begin{tabular}{|c|c|c|c|c|}
\hline Country & Country code & $B$ & $Z^{\frac{1-\alpha}{\alpha}}$ & $T F P=B Z^{\frac{1-\alpha}{\alpha}}$ \\
\hline Argentina & $\mathrm{ARG}$ & 1.383 & 0.176 & 0.458 \\
\hline Australia & AUS & 1.617 & 0.773 & 1.363 \\
\hline Bolivia & BOL & 0.498 & 0.343 & 0.249 \\
\hline Botswana & BWA & 2.345 & 0.038 & 0.328 \\
\hline Brazil & $\mathrm{BRA}$ & 1.395 & 0.123 & 0.375 \\
\hline Canada & CAN & 1.338 & 0.962 & 1.303 \\
\hline Chile & CHL & 0.526 & 0.480 & 0.326 \\
\hline China & $\mathrm{CHN}$ & 1.209 & 0.134 & 0.341 \\
\hline Colombia & COL & 0.990 & 0.151 & 0.300 \\
\hline Costa Rica & CRI & 0.915 & 0.319 & 0.438 \\
\hline Cyprus & CYP & 1.017 & 0.474 & 0.625 \\
\hline Dominican Republic & DOM & 0.830 & 0.383 & 0.445 \\
\hline Ecuador & $\mathrm{ECU}$ & 0.405 & 0.362 & 0.209 \\
\hline El Salvador & SLV & 0.940 & 0.229 & 0.366 \\
\hline France & FRA & 1.808 & 0.388 & 0.978 \\
\hline Germany & DEU & 2.016 & 0.421 & 1.148 \\
\hline Ghana & GHA & 0.553 & 0.064 & 0.103 \\
\hline Greece & GRC & 1.554 & 0.600 & 1.111 \\
\hline Guatemala & GTM & 3.794 & 0.061 & 0.691 \\
\hline Honduras & HND & 0.685 & 0.099 & 0.162 \\
\hline Hong Kong & HKG & 2.270 & 0.351 & 1.153 \\
\hline Hungary & HUN & 1.804 & 0.301 & 0.831 \\
\hline India & IND & 1.029 & 0.130 & 0.286 \\
\hline Indonesia & IDN & 1.465 & 0.042 & 0.217 \\
\hline Israel & ISR & 0.970 & 0.813 & 0.844 \\
\hline Italy & ITA & 4.748 & 0.226 & 1.829 \\
\hline Jamaica & JAM & 0.346 & 0.129 & 0.096 \\
\hline Japan & JPN & 0.904 & 0.828 & 0.797 \\
\hline Kenya & KEN & 0.607 & 0.055 & 0.104 \\
\hline Malaysia & MYS & 1.061 & 0.253 & 0.438 \\
\hline Mexico & MEX & 0.848 & 0.305 & 0.394 \\
\hline Netherlands & NLD & 2.060 & 0.524 & 1.350 \\
\hline Nicaragua & NIC & 0.168 & 0.399 & 0.093 \\
\hline Pakistan & PAK & 0.757 & 0.132 & 0.212 \\
\hline Panama & PAN & 0.387 & 0.433 & 0.224 \\
\hline Paraguay & PRY & 1.687 & 0.053 & 0.285 \\
\hline Peru & PER & 0.411 & 0.485 & 0.256 \\
\hline Philippines & PHL & 0.162 & 0.684 & 0.126 \\
\hline Portugal & PRT & 2.178 & 0.233 & 0.856 \\
\hline Singapore & SGP & 1.829 & 0.402 & 1.011 \\
\hline South Korea & KOR & 0.537 & 0.737 & 0.438 \\
\hline Sri Lanka & LKA & 0.300 & 0.318 & 0.143 \\
\hline Sweden & SWE & 1.696 & 0.553 & 1.150 \\
\hline Switzerland & $\mathrm{CHE}$ & 2.138 & 0.395 & 1.168 \\
\hline Taiwan & TWN & 1.161 & 0.781 & 0.985 \\
\hline Thailand & THA & 0.659 & 0.243 & 0.266 \\
\hline Tunisia & TUN & 0.695 & 0.213 & 0.259 \\
\hline UK & GBR & 2.164 & 0.541 & 1.447 \\
\hline Uruguay & URY & 1.469 & 0.169 & 0.476 \\
\hline USA & USA & 1.000 & 1.000 & 1.000 \\
\hline Venezuela & VEN & 0.798 & 0.421 & 0.455 \\
\hline
\end{tabular}

